\title{
4 Remilitarisierung des Kaisertums
}

Zwei gewaltsame Machtwechsel innerhalb von acht Jahren hatten das politische Klima Konstantinopels destabilisiert. Die Erhebung des Phokas schuf einen Präzedenzfall: Nachdem die hauptstädtische Konfiguration von Monarchie dem regierenden Kaiser vor allem im 6. Jahrhundert einen recht hohen Grad an Sicherheit geboten hatte, lag es nun wieder im Rahmen des Möglichen, die Machtverhältnisse in Konstantinopel durch militärischen Druck von außen zu beeinträchtigen. Während Aufstände des Heeres in den Provinzen in den Jahrhunderten zuvor die Machtverhältnisse in der Hauptstadt nicht maßgeblich ins Wanken gebracht hatten, konnte eine aggressive Positionierung von Truppenverbänden nun direkte Auswirkungen auf die politische Lage in Konstantinopel zeitigen, Eigendynamiken in Gang setzen und Entscheidungsprozesse beeinflussen. Es war jedoch nicht die militärische Schlagkraft, die das Ringen um Hoheit übers römische Reich entschied; Heereskontingente allein - ob Söldnertruppen oder reguläre Soldatenverbände - konnten nach wie vor keinen Kaiser machen, erst recht nicht in der Provinz. Die Stimmung bzw. Akzeptanz der Hauptstadt blieb weiterhin der ausschlaggebende Faktor monarchischer Herrschaft. Die Erhebung eines Kaisers konnte auch im frühen 7. Jahrhundert nur in Konstantinopel unter Beteiligung der maßgeblichen städtischen Gruppen und unter Berücksichtigung etablierter Verhaltensnormen über die Bühne gehen.

Nachdem Phokas' Erhebung neue Handlungsspielräume eröffnet hatte, gelang mit der afrikanischen Revolte und der daraus resultierenden Erhebung des Herakleios die Probe aufs Exempel. Das strategische Kalkül der Herakleioi ging auf: Nach der Rekrutierung eines aus römischen Truppen und maurischen Söldnern zusammengesetzten Heeres, der Sicherung Afrikas, Ägyptens sowie weiterer Teile der Küste des süd-östlichen Mittelmeerraumes als Machtbasis, gelang es ihnen, inneraristokratische Zerwürfnisse und bestehende Animositäten gegen Phokas für die eigenen Zwecke zu nutzten; Herakleios wurde zum Augustus gekrönt. Die Entscheidung der Usurpatoren, die Ambitionen auf den Thron durch die Konsulatsprägungen in den eroberten Gebieten deutlich herauszustellen, den eigentlichen Akt der Erhebung allerdings erst in Konstantinopel vollziehen zu lassen, erwies sich als kluger Schachzug; sie zeugt von einem eingehenden Verständnis der machtpolitischen Verhältnisse sowie einem sensiblen Umgang mit daraus resultierenden Erwartungshaltungen. Hauptstädtische Interessensgruppen wiederum zeigten ein gesteigertes Selbstbewusstsein in Hinblick auf die Beeinflussung politischer Entscheidungsprozesse: Angesichts der Instabilität von Loyalitätsverhältnissen nutzten verschiedene Individuen bzw. Gruppierungen die auftretenden Verwerfungen, um sich selbst innerhalb des kaiserlichen PatronageSystems möglichst gut zu positionieren und den Kandidaten, von dem sie sich den größtmöglichen persönlichen Vorteil erhofften, zum Kaiser zu machen.

Die gewaltsame Aneignung des Kaiseramtes durch einen Kandidaten von außerhalb der Stadt war 602 mit Phokas als praktizierbare Option in den Erfahrungsraum der Römer eingeschrieben und durch Herakleios 610 verfestigt worden. Die 
Schwelle zur Usurpation hatte sich entscheidend gesenkt. Phokas' Sturz acht Jahre nach seiner Erhebung zeigt, als wie fragil sich die Zustimmung erweisen konnte, die einem Prätendenten bei dessen Krönung ostentativ auf den Straßen der Hauptstadt, in der Hagia Sophia und dem Palast entgegengebracht worden war. Für Herakleios lag die entscheidende Herausforderung darin, in einer derart instabilen politischen Konstellation seine Position zu sichern und eine Wiederholung des Szenarios, mit dem er selbst an die Macht gekommen war, zu verhindern. Es galt einerseits, die Unterstützung der Hauptstadt zu verstetigen, und andererseits, dem Aufbegehren eines weiteren Prätendenten, welcher mit militärischen Ressourcen aus der Provinz die Stimmung in Konstantinopel zu seinen Gunsten beeinträchtigen konnte, vorzubeugen. Wie in diesem Kapitel deutlich wird, stellte Herakleios sich dieser Herausforderung, indem er im Bereich der Militär- und Familienpolitik innovative Akzente setzte.

\subsection{Die Regierung des Phokas - eine Kontrastfolie}

Um die innovativen Akzente der herakleischen Politik besonders deutlich hervortreten zu lassen, gilt es zunächst, einen Blick auf die Regierungspraxis seines Vorgängers Phokas zu werfen. ${ }^{1}$ Die folgende Analyse steht unter der Prämisse, dass es sich bei Phokas' Herrschaft bis zu dem Zeitpunkt seines Sturzes nicht um ein illegitimes Gewaltregime handelte, sondern - im Rahmen der strukturellen Voraussetzungen römischer Monarchie - um eine reguläre und legitime Regierung. ${ }^{2}$ Wie im vorigen Kapitel nachvollzogen, verunglimpfen Quellen, die nach dem Machtwechsel von 610 entstanden sind, Phokas durchweg als Tyrannen; dieser erinnerungspolitische Schachzug zielte auf die Stärkung der Herrschaft des Herakleios ab, die im Kontrast zum Vorgänger als glorreiche basileia ek theou konzipiert werden konnte. Im Vordergrund der Berichterstattung der hauptstädtischen Chronisten stehen daher meist die Auseinandersetzungen zwischen Phokas und verschiedenen Individuen und Gruppierungen in Konstantinopel, die das negative Bild untermauern, allerdings nur einen - wenn auch nicht unbedeutenden - Aspekt seiner Herrschaft darstellen. ${ }^{3}$

David M. Olster hat herausgearbeitet, dass sich der Herrschaftswechsel von 602 trotz der spektakulären Hinrichtung des Maurikios, auf die sowohl Quellen als auch Forschung in der Regel den Fokus richten, durch ein recht hohes Maß an Kontinuität

1 Dieses Unterkapitel hat nicht den Anspruch, die Phokas' Herrschaft vollumfänglich abzudecken, sondern richtet vielmehr den Fokus auf Aspekte, die für das Verständnis politischer Dynamiken in Konstantinopel besonders relevant sind.

2 Dazu siehe oben S. $104 \mathrm{f}$.

3 Das negative Phokas-Bild verstetigte sich über die Regierungszeit des Herakleios hinaus sowohl in östlichen wie auch westlichen Traditionen und wurde auch in der modernen Forschung allzu oft unkritisch rezipiert (zusammengetragen bei Meier 2014b, 139-145). Die rezente Forschung indes hat wiederholt den Versuch einer Neubewertung von Phokas' Herrschaft unternommen; siehe etwa Olster 1993, 1-21, 67-80. 
auszeichnete. ${ }^{4}$ Abgesehen von den männlichen Mitgliedern der Kaiserfamilie fielen nur einige ausgewählte Amtsträger dem neuen Regime zum Opfer: Petros (Maurikios' Bruder), Komentiolos und weitere Militärs, die sich als Befehlshaber der Balkantruppen unbeliebt gemacht hatten, sowie der Prätorianerpräfekt Konstantin Lardys, der gemeinsam mit Maurikios nach Kleinasien geflohen war. Dass Phokas einige Verwandte in höchste Ämter beförderte - seinen Bruder Domentziolos zum Magister officiorum und dessen gleichnamigen Sohn zum Curopalates und Magister militum per Orientem - entspricht wiederum typischen monarchischen Verhaltensmustern. ${ }^{5}$ Abgesehen davon behielt er die Amtsträger, die sein Vorgänger eingesetzt hatte, weitestgehend bei bzw. beförderte diese gar: Priskos, den Maurikios sowohl gegen die Perser als auch gegen die Avaren eingesetzt hatte, stieg unter Phokas zum Comes excubitorum und gar Schwiegersohn des Kaisers auf. Erst im Zuge wiederholter Unruhen und (vermeintlicher) Verschwörungen aus den Reihen der hauptstädtischen Aristokratie begann Phokas, sich prominenter Individuen, die seine Position zu untergraben drohten, zu entledigen - nicht zuletzt der restlichen Überlebenden des gestürzten Kaiserhauses. ${ }^{6}$

Im Winter 602/03 wusste Phokas Konstantinopel vorerst hinter sich - zumindest die Mehrheit der Bevölkerung, deren Stimmung sich als maßgeblich für die Besetzung des Thrones erwiesen hatte. Doch bereits kurz nach seiner Krönung sollte dem ehemaligen Zenturio von verschiedenen Seiten Widerstand entgegenschlagen; es begann mit Unruhen im Heer: Im Laufe des Jahres 603 brachte der römische General Narses Edessa in Mesopotamien in seine Gewalt und nahm mit der Bitte um militärische Unterstützung Kontakt zum Perserkönig Chosroes II. auf. Im Gegensatz zu den Meutereien der vergangenen Jahrzehnte ging es nun nicht um Fragen der Truppenversorgung; Narses erhob sich stattdessen dezidiert gegen Phokas, indem er sich auf die Rechtmäßigkeit der Familie des gestürzten Maurikios berief. ${ }^{7}$ Der Aufstand in Edessa stand offenbar mit dem Auftauchen eines Mannes in Verbindung, der sich als Maurikios' Sohn Theodosios ausgab und behauptete, dem Massaker an der kaiserlichen Familie entkommen zu sein - ob es sich dabei tatsächlich um den 591 zum Augustus gekrönten Sohn des Maurikios handelte, war wohl nicht einmal den Zeitgenossen ganz klar. ${ }^{8}$

4 Olster 1993, 67-69; dazu auch De Vleeschouwer 2019, $445 \mathrm{f}$.

5 PLRE IIIA, Domnitziolus 1 und 2 (417f.); ein weiterer Bruder des Phokas, Komentiolos (PLRE IIIA, Comentiolus 2 [326]) befehligte 610 das im Osten stationierte Heer; siehe zu Letzterem Kaegi 1973, 308 310 und allgemein zu Phokas’ Förderung der eigenen Familie ebd. 312.

6 Olster 1993, 69-72.

7 Zur Revolte des Narses siehe Sebeos 31 (Thomson/Howard-Johnston I, 58); Theoph. Conf. AM $6095-$ 6097 (De Boor 294-302); Mich. Syr. 10.25 (Chabot II, 379); Stratos 1968, 59-61; Kaegi 1981, 140 f. und Olster 1993, 82-89.

8 Gemäß Sebeos krönte Narses den angeblichen Theodosios und präsentierte diesen dem Chosroes, der persönlich nach Edessa kam (Sebeos 31 [Thomson/Howard-Johnston I, 58]); außerdem soll Ps.Theodosios mit dem persischen Heer nach Armenien vorgerückt sein, wo er sich den Bewohnern von Karin als Kaiser präsentierte (Sebeos 33 [Thomson/Howard-Johnston I, 63]). Laut Anon. Guidi (Nöldeke 
Angesichts des Kaiserwechsels in Konstantinopel witterte auch Chosroes selbst die Gunst der Stunde. Die machtpolitische Konstellation zwischen den beiden Großmächten hatte sich gegenüber dem Ende des vorigen Jahrhunderts umgekehrt: Interne Konflikte schwächten nun das römische Reich, dessen militärische Kräfte zusätzlich durch die Auseinandersetzungen mit den Avaren an der Donaugrenze beansprucht wurden. ${ }^{9}$ Abgesehen von der vermeintlichen Loyalität gegenüber seinem einstmaligen Wohltäter Maurikios sah Chosroes nun die Chance, den Spieß umzudrehen und die Gebiete, die er 591 als Gegenleistung für römische Unterstützung hatte abtreten müssen, zurückzugewinnen. ${ }^{10}$ Während sich Narses in Edessa nicht halten konnte - Phokas' Neffe Domentziolos brachte die Aufständischen zum Aufgeben und führte Narses nach Konstantinopel, wo ihn das Todesurteil erwartete -, verzeichneten die persischen Truppen unter der Führung des Großkönigs schnell erste Erfolge. Im Jahr 604 fiel nach längerer Belagerung die umkämpfte Grenzfestung Dara, die erst unter Maurikios wieder in römische Hände gekommen war. ${ }^{11}$ Die Auseinandersetzungen zwischen den beiden Großmächten beschränkten sich allerdings während der frühen Regierungsjahre des Phokas auf die mesopotamische Grenzregion; von weitreichenden Eroberungen sollten die Ostprovinzen noch einige Jahre verschont bleiben. ${ }^{12}$

In diesem Zusammenhang ist bemerkenswert, dass Phokas nach seiner Krönung die Hauptstadt bzw. deren direktes Umland trotz der erneut aufflammenden Unruhen in den Provinzen offenbar nicht mehr verließ. Sein Vorgänger Maurikios hatte wiederholt versucht, sich entgegen monarchischer Gewohnheiten des 5. und 6. Jahrhunderts durch persönliche Vorstöße nach Thrakien der Armee anzunähern. Nicht zuletzt die deutliche Missbilligung, mit der das hauptstädtische Palastumfeld auf derartige Aktivität reagierte, hatte ihn jedoch dazu gezwungen, seine Unternehmungen einzu-

15f.) veranlasste Chosroes gar, den angeblichen Theodosios vom nestorianischen Katholikos in einer Kirche nach römischer Sitte krönen zu lassen. Er soll ihm ein Heer gestellt haben, mit dem Ps.Theodosios nahe Dara auf römische Truppen traf, diesen allerdings unterlag; ähnlich auch die Chronik von Seert (Scher 500f.), gemäß der sich Chosroes mit Unterstützung des Katholikos durch einen Brief an die Römer wandte und forderte, Theodosios solle seinem Vater auf dem Thron folgen.

9 Theoph. Conf. AM 6096 (De Boor 292): nach einem Friedensvertrag mit dem Khagan konnte Phokas die Truppen an die Kriegsschauplätze im Osten schicken.

$10 \mathrm{Zu}$ der Frage nach der Motivation des Chorsroes II. siehe De Vleeschouwer 2019, 439-441.

11 Die syrischen Quellen datieren die Einnahme von Dara auf 604, so etwa Mich. Syr. 10.25 (Chabot II, 378); Theoph. Conf. AM 6098 (De Boor 293) dagegen ins Jahr 605/6; siehe dazu Mango/Scott 1997, 422 Anm. 4; zur Datierung auch Flusin 1992 II, 71-74 und Olster 1993, 95.

12 Der Konflikt zwischen Rom und Persien wird bei Bonner 2019, 267-311 aus sassanidischer Sicht detailliert beschrieben. Sowohl die Abfolge als auch die absolute Chronologie des frühen Stadiums des römisch-persischen Krieges ist umstritten; zur Quellenlage und einer Rekonstruktion siehe Stratos 1968, 58-66; Flusin 1992 II, 70 -83; Bonner 2019, 280 -282; Olster 1993, 81-97; ebd. 98 - 100 die tabellarische Auflistung aller relevanten Quellen mit den jeweiligen Datierungen der Ereignisse. Zu der Eroberung von Mesopotamien und Armenien siehe auch De Vleeschouwer 2019, 441-444; zu den Konflikten zwischen Römern und Persern im 6. und frühen 7. Jahrhundert siehe den Überblick in Meier 2019a, $1020-1035$. 
stellen. ${ }^{13}$ Phokas machte keine Anstalten, an das Ringen seines Vorgängers um innovative Positionierungsmöglichkeiten anzuknüpfen. Trotz oder gerade wegen seines militärischen Hintergrundes konzentrierte Phokas sich auf den städtischen Interaktionsraum; der Unterstützung des Balkanheeres, dem er selbst entstammte, schien er sich sicher zu sein und erachtete es offenbar nicht als notwendig, im militärischen Sektor persönlich aktiv zu werden. Die Revolte des Generals Narses konnte eingehegt werden. Nachdem der Kaiser das Balkanheer 603 in Folge eines Friedensschlusses mit dem Avaren-Khagan an den östlichen Kriegsschauplatz verlegt hatte, ging von den Truppen, die gegen die Perser kämpften, offenbar keine weitere Bedrohung für Phokas aus. ${ }^{14}$

Ein in der Forschung viel diskutiertet Aspekt von Phokas' Herrschaft ist dessen enge Beziehung zum Papst in Rom. Dass der frisch gekrönte Kaiser sein Bildnis und das seiner Ehefrau, der Augusta Leontia, nach Rom schickte, wo Papst Gregor diese feierlich empfing und im kaiserlichen Palast auf dem Palatin aufstellen ließ, ${ }^{15}$ entspricht gängiger kaiserlich-diplomatischer Praxis. ${ }^{16}$ Auch die durchweg positive Reaktion des Gregor auf den Machtwechsel in Konstantinopel - in einem seiner Briefe preist er die Erhebung des Phokas gar als Befreiung von Maurikios ${ }^{17}$ - überrascht nur vordergründig. Während die ältere Forschung sich schwer tat, ihr Bild von Phokas als blutrünstigem Tyrannen mit dessen Bestätigung durch Gregor zu vereinbaren, haben jüngere Publikationen eine Reihe an Faktoren ins Spiel gebracht, die die Kommunikation zwischen Kaiser und Papst in anderem Lichte dastehen lassen. ${ }^{18}$ Zunächst ist erneut festzuhalten, dass Phokas' Krönung von den Zeitgenossen als reguläres Prozedere und nicht etwa als illegitime Ermächtigung wahrgenommen wurde; Gregor hatte daher keinen Grund, die Geschehnisse in Konstantinopel per se zu verurteilen. Dazu kommt, dass das Verhältnis zwischen Konstantinopel und Rom unter Maurikios einen empfindlichen Dämpfer erlitten hatte. Im Zusammenhang mit dem Drei-KapitelStreit weigerten sich die Bischöfe von Mailand, Aquileia und Istria, den päpstlichen Direktiven nachzukommen; im Jahr 553 kam es zum Istrischen Schisma. Der Konflikt gewann an politischer Brisanz, als die abtrünnigen Bischöfe bei den langobardischen Königen Anklang fanden. In seinen Bemühungen um die Beilegung des Schismas setzte der Papst Gregor auf Konstantinopolitaner Unterstützung in Person des in Ravenna residierenden Exarchen. Der Exarch Smaragdus, der sich gegenüber der römischen Sache als offen gezeigt hatte, wurde von Maurikios abgesetzt; bei seinem

13 Dazu siehe oben S. $74 \mathrm{f}$.

14 Theoph. Conf. AM 6096 (De Boor 292) zur Verlegung des Balkanheeres.

15 Greg. Epist. 13.1 (Hartmann); die Bilder erreichten Rom am 25. April 603.

16 Phokas schickte auch einen Gesandten (Lilis) zu Chosroes II., um diesen von seiner Erhebung zu unterrichten, siehe Theoph. Sim. Hist. 8.15.2-6.

17 Glückwunschschreiben des Gregor an Phokas: Greg. Epist. 13.34 (Hartmann) = 13.32 (Norberg); außerdem Greg. Epist. 13.41 (Hartmann) = 13.39 (Norberg). Auch Phokas' Frau Leontia erhielt einen Brief von Gregor: Greg. Epist. 13.42 (Hartmann) = 13.40 (Norberg). Siehe zu diesen Briefen ausführlich Olster 1993, 169 - 172; Ekonomou 2007, 46 f.; siehe auch Meier 2014b, 140 f. Anm. 5 zu den Reaktionen in der Forschung.

18 Vor allem Ortenberg West-Harling 2016; De Vleeschouwer 2019; vgl. auch Meier $2014 b$. 
Nachfolger Romanus (im Amt 589-596) stieß Gregor mit seinen Anliegen auf taube Ohren. ${ }^{19}$ Die bereits angespannten Beziehungen erreichten einen weiteren Tiefpunkt, als Maurikios den Patriarchen von Konstantinopel mit dem Attribut ,ökumenisch“ versah und damit dessen Hoheit über den Papst in Rom feststellte. Auch Gregors Versuche, die Konflikte mit den Langobarden, die Italien bedrohten, auf friedlichem Wege beizulegen, trafen auf Seiten der von Konstantinopel entsandten Amtsträger nicht auf die erhoffte Unterstützung. ${ }^{20}$ Vor diesem Hintergrund ist es kaum verwunderlich, dass Gregor angesichts des Machtwechsels am Bosporus auf eine neuerliche Verbesserung seiner Beziehung zum Kaiser - und damit eine Stärkung seiner Position in Italien - setzte.

Der frisch gekrönte Phokas sollte Gregors Hoffnungen nicht enttäuschen. Zunächst ersetzte er den Exarchen Callinicus mit Smaragdus, der sich in seiner ersten Amtszeit bereits als kooperativ gegenüber dem Heiligen Stuhl in Rom erwiesen hatte. Eben dieser Smaragdus war es auch, der dem Phokas im Jahr 608 ein Ehrenmonument auf dem Forum Romanum errichten ließ - das letzte seiner Art in der Antike -, von dem heute noch der Säulenschaft in situ zu sehen ist. Die auf der Basis angebracht Inschrift feiert Phokas für seine Milde und Frömmigkeit sowie seine Bemühungen um Frieden in Italien. ${ }^{21}$ Phokas setzte sich nicht nur für eine Beruhigung der Konfrontation mit den Langobarden ein, sondern machte auch die von Maurikios betroffene Entscheidung hinsichtlich der kirchlichen Hierarchie rückgängig: In einem kaiserlichen Edikt des Jahres 607 betonte Phokas die Vorrangstellung des Papstes gegenüber dem Patriarchen von Konstantinopel. ${ }^{22}$ Darüber, wie der Konstantinopolitaner Klerus einen derartigen Schritt aufnahm, lässt sich aufgrund des Mangels an Quellen nur spekulieren; er wird allerdings kaum zu Phokas' Beliebtheit in der Hauptstadt am Bosporus beigetragen haben. ${ }^{23}$ Im folgenden Jahr veranlasste Phokas einen entscheidenden Schritt in Richtung der Christianisierung paganer Monumente im Römischen Stadtzentrum, indem er Gregors Nachfolger Bonifaz das Pantheon überließ; 609 wurde der ehemalige Tempel zur Kirche Santa Maria ad Martyres um-

19 Zum Istrischen Schisma und der Positionierung des Maurikios in diesem Zusammenhang siehe Ortenberg West-Harling 2016, 200 f.; De Vleeschouwer 2019, 455; zu dem Exarchen Romanus siehe Ravegnani 2011, 54-63.

20 Ortenberg West-Harling 2016, 201.

21 CIL 6, 1200; zu Smaragdus siehe Ravegnani 2011, 50 - 54 (erste Amtszeit); 66 - 68 (zweite Amtszeit). 22 Lib. Pont. 68 (Bonifacius III); Dölger 1976, Nr. 155; Olster 1993, 169; Ekonomou 2007, 49 weist darauf hin, dass Phokas damit Justinian folgte.

23 Kurz zuvor war Phokas offenbar mit dem Patriarchen Kyriakos aneinandergeraten, als Kyriakos sich Phokas’ Versuch, Maurikios' Witwe Konstantina aus der Hagia Sophia zu entfernen, widersetzte (Theoph. Conf. AM 6098 [De Boor 293]). Kyriakos verstarb im Jahr 606; ihm folgte Thomas nach, zu dessen Verhältnis zu Phokas keine Informationen erhalten sind. Nach Thomas' Tod wurde Sergios am 18. April 610 zum Patriarchen erhoben, der sich als Schlüsselfigur in Herakleios' Regierung erweisen sollte; zu Sergios siehe Van Dieten 1972, 1-56; ebd. 1 zur Erhebung. Zu Phokas' Religionspolitik, die unter anderem eine erneute Verschärfung des Konfliktes mit den miaphysitischen Gemeinden im Osten mit sich brachte, siehe Stratos 1968, $74 \mathrm{f}$. 
geweiht und von Phokas mit reichen Geschenken ausgestattet. ${ }^{24}$ Die zwischen 602 und 610 amtierenden Päpste konnten also von der Herrschaft des Phokas deutlich profitieren; ihre vollumfängliche Unterstützung dieses Kaisers bedarf keiner weiteren Erklärung. Warum Phokas sich so deutlich für italische Belange einsetzte und dabei auch eine Verstimmung des Patriarchen von Konstantinopel in Kauf nahm, ist dagegen weniger offensichtlich. Deutlich wird zumindest, dass es der Sicherheitslage im von Langobarden bedrohten Italien zuträglich war, wenn Kaiser und Papst an einem Strang zogen. Dies mag für Phokas nicht zuletzt vor dem Hintergrund bedeutsam gewesen sein, dass sich im Osten erneut der Konflikt mit den Persern entfacht hatte und Ressourcen bedacht eingesetzt werden mussten. ${ }^{25}$

Die Päpste in Rom waren nicht die einzige spirituelle Autorität, zu der Phokas in guter Beziehung stand. Die Quellen geben Hinweise darauf, dass der Kaiser engen Kontakt mit einigen prominenten Heiligen Männern pflegte - einer mit religiösem Prestige und Autorität ausgestatteten Personengruppe, deren Nähe und Unterstützung auch seine Vorgänger stets gesucht hatten. ${ }^{26}$ Die Vita des Heiligen Theodor von Sykeon, vollendet nach Herakleios' Tod, berichtet, wie Phokas den Heiligen im hauptstädtischen Palast empfing und durch ihn von einer Krankheit geheilt wurde; Theodors Ermahnung, Phokas solle vom Blutvergießen ablassen, um nicht Gottes Zorn auf sich zu ziehen, ist dabei aller Wahrscheinlichkeit nach der retrospektiven Verunglimpfung des Kaisers als mordlustiger Tyrann geschuldet. ${ }^{27}$ Nicht nur Phokas selbst, sondern auch dessen bereits erwähnter Neffe Domentziolos stand in engem Kontakt mit Theodor; nach dem Machtwechsel von 610 setzte sich der Heilige gar bei Herakleios für seinen Schützling ein und verhinderte dessen Hinrichtung. ${ }^{28}$ Ein Gedicht des Sophronios, des späteren Patriarchen von Jerusalem, ist außerdem ein Indiz dafür, dass Phokas mit dem Heiligen Kosmas in Kontakt stand. ${ }^{29}$ Der fromme Kaiser habe so das Gedicht - im Zusammenhang mit dem Prozess um Menas, einem Abt aus Alexandria, vom Heiligen Kosmas Rat erbeten. Kosmas' göttlich inspirierte Erkenntnis von Menas' Unschuld habe Phokas sich zu Herzen genommen und den Abt umgehend freigesprochen. Im Gegensatz zu der Vita des Theodor wurde Sophronios' Gedicht nach dem Machtwechsel von 610 nicht angepasst und bietet damit ein authentisches Zeugnis davon, wie der Kaiser von seinen Zeitgenossen im monastischen Milieu dar-

24 Lib. Pont. 69 (Bonifacius IV); Ekonomou 2007, 50.

25 Siehe De Vleeschouwer 2019, 457 zu dem „mutually beneficial relationship“ zwischen Kaiser und Papst.

26 Zur Interaktion von Kaiser und Heiligen Männern siehe Pfeilschifter 2013, 434-450.

27 Vit. Theod. Syk. 133; siehe dazu Olster 1993, 174 f. und Meier 2014b, 156 f. mit Anm. 51. Maurikios hatte bereits mit Theodor in Kontakt gestanden (Vit. Theod. Syk. 54, 82, 97) und auch Herakleios sollte dessen Nähe suchen (ebd. 154f., 166); zu Theodor von Sykeon und Phokas siehe auch Van Ginkel 2002, $229-231$.

28 Vit. Theod. Syk. 140, 152.

29 Soph. Anacr. 21. 
gestellt werden konnte: nämlich entlang traditionell enkomiastischer Kategorien als

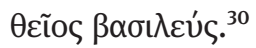

Trotz der problematischen Quellenlage ist zumindest in Grundzügen nachzuvollziehen, wie Phokas sich im hauptstädtischen Sozialgefüge positionierte. Eine Notiz des Theophanes lässt darauf schließen, dass er an Weihnachten 603, etwas mehr als ein Jahr nach seiner Krönung, den Konsulat antrat und dieses Ereignis feierte, indem er traditionsgemäß durch die Straßen der Hauptstadt zog und die versammelte Bevölkerung mit Spenden bedachte. Der Antritt dieses Amtes, das spätestens seit Justin II. mit kaiserlicher Würde im Allgemeinen und der Erhebung eines neuen Kaisers im Speziellen verbunden war, wurde auch auf Münzen angezeigt: Die Averse von Gold- und Bronzeprägungen zeigen Phokas in Konsulatstracht. ${ }^{31}$

Beim Blick auf die Münzen sticht außerdem ins Auge, dass Phokas im Gegensatz zu seinen Vorgängern ein Individualportrait auf den Münzen abbilden ließ. Nachdem die Kaiser des 5. und 6. Jahrhunderts allesamt idealisiert (d. h. entindividualisiert) und bartlos auf den Aversen der verschiedenen Nominale erschienen waren, kann der charakteristische Spitzbart des Phokas kaum anders denn als bewusste Abkehr von dieser Bild-Tradition gewertet werden. ${ }^{32}$ Philip Grierson schlägt vor, die bärtige Darstellung als Verweis auf Phokas’ „plebeian background” und seine abrupte Erhebung zum Kaiser, die keine Zeit für „cultural acclimatization” geboten habe, zu deuten. ${ }^{33}$ Dabei scheint Grierson allerdings zu vernachlässigen, dass es sich bei Münzbildern kaum um kontingente Nebenprodukte politischer Prozesse handelte, sondern vielmehr um bewusst komponierte Äußerungen der kaiserlichen Repräsentationsstrategie. Phokas war es offenbar daran gelegen, sich zu einem gewissen Grad von seinen Vorgängern abzuheben. ${ }^{34}$

$\mathrm{Zu}$ beachten ist in diesem Zusammenhang jedoch nicht nur Phokas' Repräsentation, sondern auch die Modi seiner Interaktion mit den herrschaftsrelevanten Gruppen in Konstantinopel. Nachdem die Krönung und sein Einzug in die Stadt weitestgehend ohne Störungen abgelaufen waren, sah sich der neue Kaiser schnell mit wiederkehrenden Problemen konfrontiert: Einerseits formierte sich in aristokrati-

30 Soph. Anacr. 21.99. Eine eingehende Analyse des Gedichtes findet sich bei Olster 1993, 172-174, 182, der darauf hinweist, dass der Charakter des Gedichtes ein primär hagiographischer ist; herausragender Protagonist ist demnach nicht Phokas, sondern der göttlich inspirierte Heilige Kosmas. Das Gedicht offenbare somit eher einen Einblick ins monastische, nicht unbedingt in hauptstädtisch-palatiale Milieu. 31 Theoph. Conf. AM 6096 (De Boor 420); siehe Olster 1993, 178f. mit Fig. 3f.; zu der Verbindung von Konsulat und Erhebung siehe ebd. 176-179.

32 DOC II.1, 88-94 zu Portraits auf frühbyzantinischen Münzen. Zu Phocas’ Münzen siehe MIB II, 76-83, Taf. 29-36; DOC II.1, 147-206, Taf. 1-7.

33 DOC II.1, 89f. (Zitat 90). Grierson verweist außerdem darauf, dass ab dem frühen 7. Jahrhundert Christus vermehrt mit Bart dargestellt wurde, und äußert die Vermutung, dass Phokas sich daran orientiert haben könnte. Gegen die These von Grierson, die Darstellung sei der abrupten Erhebung geschuldet, spricht auch, dass Phokas Zeit seiner Herrschaft nicht von dieser Darstellungskonvention abrückte.

$34 \mathrm{Zu}$ Münzen als Kommunikationsmedium siehe unten S. 168-170. 
schen Kreisen eine Opposition, die sich formal auf das Erbe des ermordeten Maurikios berief; ${ }^{35}$ andererseits erwies sich die Kommunikation zwischen Phokas und der hauptstädtischen Bevölkerung als zunehmend dysfunktional. ${ }^{36}$ Obwohl Phokas einen Großteil der hohen Amtsträger, die sein Vorgänger Maurikios eingesetzt hatte, beibehielt, hatte der unerwartete Herrscherwechsel von 602 die Hauptstadt in Gewinner und Verlierer gespalten und damit die Dynamiken des Patronagesystems, das sich um den Kaiser rankte, angeheizt. ${ }^{37}$ Widerstand gegen Phokas formierte sich jedoch nicht etwa in einer standesbewussten hauptstädtischen Elite, die den Emporkömmling nicht in ihren Reihen akzeptierte; nachdem Maurikios' Sturz Bewegung in die politische Hierarchie gebracht hatte, versuchten Individuen bzw. Fraktionen innerhalb der hauptstädtischen Amtselite vielmehr, sich gewinnbringend zu positionieren bzw. die machtpolitische Zurücksetzung, die ihnen wiederfahren war, zu kompensieren. ${ }^{38}$

Im Zentrum des Widerstandes, der sich kurz nach Phokas’ Krönung zu formieren begann, standen Germanos, der Schwiegervater von Maurikios' ältestem Sohn Theodosios, und Konstantina, Maurikios' Witwe. Nachdem Germanos bereits nach Maurikios' Flucht aus der Hauptstadt im November 602 seine Ambitionen auf den Kaiserthron erklärt hatte, versuchte er im Jahr 603 erneut, das hauptstädtische Volk, ohne dessen Rückendeckung ein Regimewechsel undenkbar war, für sich zu gewinnen. In seinem Zusammenschluss mit Konstantina berief er sich auf die Rechtmäßigkeit der gewaltsam gestürzten Kaiserfamilie, scheiterte aber wie bereits im Jahr zuvor an der entschiedenen Ablehnung der grünen Zirkuspartei, die weder ihm noch Konstantina wohlgesinnt war. Phokas stellte die beiden Unruhestifter daraufhin in Klöstern kalt. ${ }^{39}$ Zwei Jahre später flammte der Konflikt jedoch erneut auf: Hochrangige Amtsträger, unter ihnen der Prätorianerpräfekt Theodor, schmiedeten Pläne, Phokas während der Pferderennen in dessen Loge im Hippodrom zu ermorden. Als die Verschwörung aufgedeckt wurde, nutzte Phokas die Gelegenheit, sich einer ganzen Reihe von Männern, die bereits unter Maurikios aufgestiegen waren und nach dem Machtwechsel vorerst ihre Positionen beibehalten hatten, zu entledigen. Auch Germanos sowie die letzten weiblichen Überlebenden des ehemaligen Kaiserhauses - Konstantina und ihre Töchter -, fielen den Säuberungen zum Opfer. ${ }^{40}$ Erneut fanden die Hinrichtungen vor den Augen der Öffentlichkeit statt. ${ }^{41}$

35 Zu der Opposition von Seiten der Aristokratie siehe Olster 1993, 69- 72 und Pfeilschifter 2013, 589 f., 593. $36 \mathrm{Zu}$ den Unruhen und Ausschreitungen in Konstantinopel unter Phokas siehe Olster 1993, 76-79; Pfeilschifter 2013, 590 - 592; vgl. auch Al. Cameron 1976, 253 f., 282f. und Roberto 2010, 59 f.

37 Die „dynamic of patronage and faction”, die Phokas’ Herrschaft beeinträchtigte, arbeitet detailliert Olster 1993, 68-80 heraus (Zitat 76).

38 Vgl. die Rekonstruktion von Phokas' Regierung bei Olster 1993, 165-182.

39 Chron. Pasch. AD 603 (695); Theoph. Conf. AM 6098 (De Boor 293).

40 Auch hier soll der Konflikt mit dem angeblichen Überleben des Theodosios in Verbindung gestanden haben, siehe Theoph. Conf. AM 6099 (De Boor 294).

41 Chron. Pasch. AD 605 (696); Theoph. Conf. verteilt den Bericht über die Verschwörung auf zwei Einträge: AM 6099 (De Boor 294) und AM 6101 (De Boor 297f.). Zu der Opposition von Seiten der Aristokratie vgl. Olster 1993, 69-72 und Pfeilschifter 2013, 589f., 593. 
In diesem Zusammenhang ist zu beobachten, dass wiederholt der Verweis auf das Erbe des Maurikios instrumentalisiert wurde, um Unterstützung zu mobilisieren. Basis bzw. Hintergrund dieser Strategie war das Gerücht, Maurikios’ ältester Sohn, der Augustus Theodosios, sei dem Massaker vom November 602 entkommen und habe sich nach Persien absetzen können, um Chosroes II. um Hilfe zu ersuchen. Armenische und syrische Quellen berichten von dem Auftauchen des Theodosios im Grenzgebiet zwischen dem römischen und persischen Reich im Zusammenhang mit dem erneuten Ausbruch des Krieges zwischen den beiden Großmächten. Laut der GuidiChronik soll Theodosios gar mit Chosroes' Unterstützung vom nestorianischen Katholikos zum Kaiser gekrönt worden sein; Sebeos berichtet, Theodosios habe sich den Bewohnern des armenischen Karin als Kaiser präsentiert. ${ }^{42}$ In hauptstädtischen Quellen findet das Auftreten des mutmaßlichen Theodosios indes nur verhältnismäßig geringe Beachtung. ${ }^{43}$ Dies mag entweder daran liegen, dass das Gehabe an der Grenze schlichtweg keine direkten politischen Auswirkungen auf Konstantinopel zeitigte (Kaiser war nur, wer Konstantinopel kontrollierte, und Theodosios war weit davon entfernt), oder dass das Regime alles daran tat, um derartige Nachrichten zu unterdrücken. ${ }^{44}$ Theophanes Confessor bringt immerhin den erneuten Ermächtigungsversuch, den Germanos und Konstantina schlussendlich mit ihrem Leben bezahlten, damit in Verbindung, dass sich in Konstantinopel das Gerücht von Theodosios’ Überleben verbreitet habe. ${ }^{45}$ Nicht zuletzt die harschen Maßnahmen, mit denen Phokas der Intrige begegnete, sprechen dafür, dass das Gerücht trotz der Unbeliebtheit der gestürzten Kaiserfamilie auch in der Hauptstadt eine gewisse Wirkung entfalten konnte.

Die Frage, ob es sich bei dem jungen Mann tatsächlich um den Sohn des Maurikios handelte, ist nicht nur schwerlich zu beantworten, sondern im Rahmen dieser Arbeit geradezu irrelevant. Um machtpolitisches Ringen erneut zu entfachen, reichte

42 Anon. Guidi (Nöldeke 15f.); Sebeos 31 (Thomson/Howard-Johnston I, 58): Krönung des Theodosios durch den aufständischen General Narses; 33 (Thomson/Howard-Johnston I, 63): Theodosios mit dem persischen Heer in Armenien; siehe auch Chronik von Seert (Scher 500f.); dazu Booth 2019, bes. 794807. Der Umstand, dass verschiedene östliche Quellen unabhängig voneinander das Auftauchen des Theodosios thematisieren, zeigt, welches Aufsehen dies dort erregte. Ob der Bericht von einer Krönung authentisch ist, bleibt allerdings dahingestellt. Theodosios war bereits gekrönt worden, ein erneuter Vollzug des Rituals also eigentlich nicht notwendig; dass er sich in der Provinz als Kaiser präsentierte, ist indes durchaus plausibel. Zur weiteren Theodosios-Überlieferung im Osten siehe auch Schilling 2008, $282 \mathrm{f}$.

43 Nur Theoph. Conf. AM 6095 (De Boor 291), der sich bei der Zusammenstellung seiner Chronographie unter anderem der syrischen Tradition bediente, verweist darauf. $\mathrm{Zu}$ der Theodosios-Überlieferung siehe Stratos 1968, 55f.; Olster 1993, 89, $91 \mathrm{f}$.

44 Auch für Herakleios war die Möglichkeit, dass Theodosios noch am Leben war, äußerst unangenehm; Theophylakt Simokattes (Hist. 8.13.3-6, 15.8f.), der dem herakleischen Regime nahestand, tat alles daran, die Gerüchte zwar aufzugreifen, dann aber zu entkräften, indem er betont, dass auch Theodosios mit seinem Vater hingerichtet worden sei.

45 Theoph. Conf. AM 6099 (De Boor 294f.); vgl. auch (weniger konkret) Theoph. Sim. Hist. 8.15.8. f.; vgl. Chron. Pasch. AM 605. 
das Gerücht bzw. die durchaus realistische Möglichkeit seines Überlebens. Theodosios hatte als Sohn des ehemaligen Kaisers zwar kein wie auch immer geartetes Recht auf den Thron, aber dynastisches Prestige wog durchaus schwer. Die angebliche Präsenz eines weiteren Augustus - Theodosios war von seinem Vater 591 in Konstantinopel gekrönt worden -, diente verschiedenen Akteuren als Anlass, um in Opposition zu Phokas eine erneute Verschiebung der politischen Machtkonstellation anzustreben: sowohl Akteuren innerhalb der hauptstädtischen Elite als auch dem Perserkönig Chosroes II., der die Konstellation nutzte, um unter Berufung auf seine Bindung zu Maurikios' Familie Gebietsverluste wieder gutzumachen. Doch unter welchen Vorwänden auch immer - den Phokas-Gegnern in Konstantinopel gelang es vorerst nicht, die nötige Unterstützung zu mobilisieren.

Zusätzlich zu den Intrigen aus der hauptstädtischen Elite erwies sich auch die Stimmung innerhalb der hauptstädtischen Bevölkerung als fragil. Selbst die grüne Zirkuspartei, die Phokas' Krönung noch maßgeblich mit eingeleitet hatte, zeigte sich wankelmütig. Erneut erschütterten Aufstände die Hauptstadt; bereits im Jahr 603 gingen Teile der Mese sowie das Prätorium in Flammen auf. ${ }^{46}$ Derartige Unruhen sind zu einem gewissen Grad als typische Ausschreitungen der Konstantinopolitaner Demen zu interpretieren; nicht unbedingt gegen den Kaiser direkt gerichtet, konnten sie auch zwischen verfeindeten Fraktionen innerhalb der Bevölkerung aufflammen in der Regel zwischen der grünen und der blauen Zirkuspartei. ${ }^{47}$ Davon abgesehen sind allerdings auch konkrete Konfrontationen zwischen Kaiser und Bevölkerung nachzuvollziehen. Phokas überreizte die Gunst, die ihm im November 602 noch recht einmütig entgegengebracht worden war. Als er im Jahr 607 den einflussreichen General Priskos mit seiner Tochter Domentzia verheiratete, kam es während der Hochzeitsfeierlichkeiten zum Eklat: Für die Spiele im Hippodrom installierten die Zirkusparteien Bildnisse des frisch vermählten Paares neben denen des Phokas und seiner Frau, der Augusta Leontia. Phokas empfand eine derartige Aufstellung, die als recht unverhohlener Kommentar zur Nachfolgeregelung verstanden werden konnte, als anmaßend und drohte den Verantwortlichen mit harten Strafen; nur der Druck der versammelten Bevölkerung im Hippodrom ersparte den beiden Demarchen, den Sprechern der Zirkusparteien, die Todesstrafe. ${ }^{48}$ Der Vorfall beeinträchtigte nicht nur das Verhältnis zwischen Phokas und der Bevölkerung, sondern führte auch dazu, dass der gekränkte Priskos sich von seinem Schwiegervater abwandte und schließlich entscheidend zum Gelingen der Usurpation des Herakleios beitrug. Während der Konflikt anlässlich der Hochzeitsfeier oberflächlich noch hatte entschärft werden können, kam es wenige Jahre darauf zur Eskalation im Hippodrom: Johannes von

46 Chron. Pasch. AD 603 (De Boor 695), bei dem Aufstand verbrannte der Demarch der Grünen, Johannes Kroukis, auf der Mese, siehe zum Aufstand der „Grünen unter Kroukis“ auch die Doctrina Jacobi (Dagron/Déroche 128).

47 Siehe Pfeilschifter 2013, 590 f. mit Verweis auf Al. Cameron 1976, 282.

48 Zum Eklat bei der Hochzeit siehe Joh. Ant. fragm. 319; Theoph. Conf. AM 6099 (De Boor 294); vgl. Nikeph. Brev. 1.; vgl. Al. Cameron 1976, 253 und Pfeilschifter 2013, 593-596. 
Antiochia und Theophanes Confessor, der das Ereignis ins Jahr 610 datiert, überliefern den gegen Phokas gerichteten Schmähgesang: „Wieder einmal hast du aus dem Becher getrunken. Wieder einmal hast du den Verstand verloren. “49 Der im 11. Jahrhundert schaffende Chronist Kedrenos gibt darüber hinaus entscheidende Informationen zum Kontext: Phokas sei zu spät und offensichtlich betrunken zu den Spielen erschienen; einer Aufforderung des versammelten Volkes, sich zu erheben, kam er nicht nach, woraufhin ihm die bereits zitierte Beleidigung entgegenschleudert wurde. ${ }^{50}$ Öffentliche Hinrichtungen, die der erboste Phokas daraufhin als kollektive Strafmaßnahme anordnete, führten dazu, dass die Situation nur noch weiter außer Kontrolle geriet: Die grüne Zirkuspartei setzte das Praetorium sowie weitere Gebäude der Innenstadt in Brand. Laut Theophanes soll Phokas die Grünen in Folge dessen mit Sanktionen belegt haben, indem er sie von der Ausübung öffentlicher Ämter ausschloss. ${ }^{51}$

Der Grund für die Eskalation dieses letztgenannten Konfliktes scheint, dass Phokas nicht angemessen auf die Verhaltenserwartungen seiner Gegenüber, der versammelten Bevölkerung bzw. der Zirkusparteien, einging. Das Aufeinandertreffen von Kaiser und Bevölkerung im Hippodrom hatte sich in den zweihundert Jahren der hauptstädtischen Monarchie als kommunikativer Schlüsselmoment herauskristallisiert: Sets an zeremoniellen Versatzstücken strukturierten die Interaktion zwischen dem Kaiser im Kathisma, umgeben von seiner Familie, der Amtselite und den Garden, und der Masse an Menschen auf den Rängen; gleichzeitig konnten beide Seiten auch spontan auf aktuelle Gegebenheiten reagieren und damit in einen situativen Aushandlungsprozess eintreten. ${ }^{52}$ Das Maß an Flexibilität und möglicher Spontanität durfte allerdings nicht überstrapaziert werden. Phokas missachtete basale Anforderungen an kaiserliches Verhalten: Dem Mangel an Respekt (Zuspätkommen, betrunkener Zustand) folgte die Verweigerung von Interaktion (er ging nicht auf die Impulse der Bevölkerung ein), was eine weitere Eskalationsstufe einleitete (explizite Beleidigung und Bestrafung). Als Phokas keine Gnade walten ließ, war das Ausgreifen der Gewalt geradezu unvermeidbar.

Nachdem die maßgeblichen städtischen Gruppen sich im November 602 hinter Phokas gestellt und damit den Consensus universorum demonstriert hatten, von dem der Erfolg einer Krönung abhing, genoss der Kaiser in Konstantinopel einen gewissen

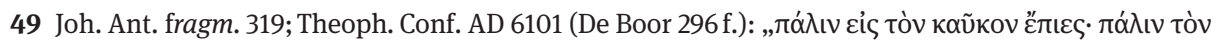

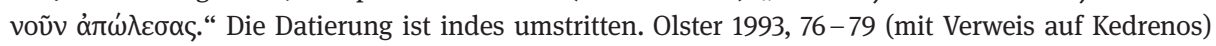
plädiert dafür, dass diese Episode im Zusammenhang mit dem Aufstand steht, der vom Chron. Pasch. ins Jahr 603 verortet wird; dagegen Pfeilschifter 2013, 590 - 592. Ich halte eine Spätdatierung gemäß Theophanes auch für wesentlich plausibler.

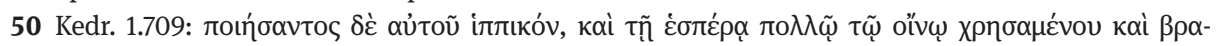

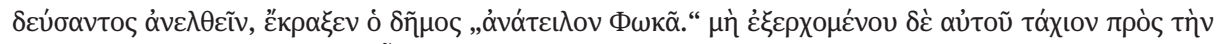

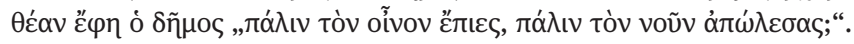

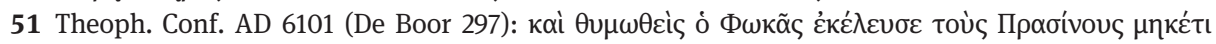

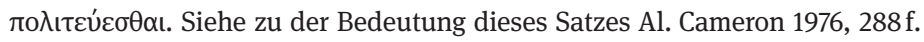

52 Zur Interaktion zwischen Kaiser und Volk im Hippodrom siehe Al. Cameron 1976, 157-192. 
Vertrauensvorschuss. ${ }^{53}$ Unsensibles, ja geradezu fahrlässiges Verhalten gegenüber der hauptstädtischen Bevölkerung untergrub allerdings sukzessive die Akzeptanzbasis seiner Herrschaft. ${ }^{54}$ Ob Phokas' Verhalten dem Umstand geschuldet war, dass er aufgrund seiner Herkunft schlichtweg nicht mit den Finessen des Protokolls vertraut war, bleibt dahingestellt; Fauxpas wie der oben geschilderte führten jedenfalls dazu, dass er selbst den Rückhalt der grünen Zirkuspartei, die maßgeblich zu seiner Erhebung beigetragen hatte, verlor. Innerstädtische Herausforderer wie Germanos hatten ihrerseits nicht die maßgebliche Unterstützung mobilisieren können; als sich jedoch Herakleios 610 mit seiner Flotte Konstantinopel näherte, bedurfte es nicht mehr viel, dass sowohl prominente Vertreter der städtischen Elite als auch der ausschlaggebende Anteil der hauptstädtischen Bevölkerung, angeführt erneut von der grünen Zirkuspartei, sich auf dessen Seite schlugen und Phokas auf verlorenem Posten zurückblieb.

Phokas gelang es nicht, die ihm im November 602 entgegengebrachte Akzeptanz zu verstetigen. Sein Scheitern lässt sich zu einem gewissen Grad mit dem Umstand begründen, dass er den Vertrauensvorschuss durch fahrlässiges Verhalten recht bald verspielte. Der Überblick über Phokas' Regierung hat allerdings auch deutlich gemacht, dass er sich als Kaiser insgesamt durch eine konservative Regierungspraxis auszeichnete: Bis auf wenige Ausnahmen, etwa der innovativen Darstellung auf Münzen, hielt er an den Handlungsmustern fest, wie sie sich im Laufe der zweihundert Jahre hauptstädtischer Monarchie als Instrumente der Herrschaftssicherung etabliert hatten. ${ }^{55}$ Die wiederholte Enttäuschung von Verhaltenserwartungen an den Kaiser in Kombination mit Phokas' Unfähigkeit, den Herausforderungen seiner Zeit mit innovativen Akzenten entgegenzutreten, bereitete die Grundlage dafür, dass Herakleios' Usurpation Erfolg haben konnte. Die Konzentration auf die Hauptstadt reichte offenbar nicht mehr aus, um den regierenden Kaiser gegen potentielle Herausforderer - vor allem Herausforderer von außerhalb - zu immunisieren.

\subsection{Vom sesshaften Kaiser zum Heerführer}

Wie bereits zu Beginn dieses Kapitels betont, lag Herakleios' zentrale Herausforderung darin, eine erneute Wiederholung des Szenarios zu verhindern, durch das er selbst auf den Thron gekommen war. Es galt, die Fehler, die Phokas Thron und Leben gekostet hatten, zu vermeiden und sowohl Konstantinopel als auch den militärischen

53 Als Phokas Maurikios' Witwe Konstantina aus der Hagia Sophia zu entfernen suchte (Theoph. Conf. AM 6098, [De Boor 293]), tat er genau das, was einige Jahre zuvor in Hinblick auf Maurikios die Stimmung in Konstantinopel hatte kippen lassen: die Missachtung des Kirchenasyls; im Gegensatz zu 602 kam Phokas aber damit davon.

54 Vgl. Mi. Whitby 2000a, 109: „Phocas seems to have been insensitive to the niceties of the emperor's ceremonial existence within the capital ...”

55 Vgl. Olster 1993, 184: „He [Phocas] appears as a typical sixth-century ruler confronted with challenges that traditional solutions could no longer solve.“ 
Sektor, der sich zuletzt vermehrt als Risikofaktor für die Stabilität monarchischer Herrschaft erwiesen hatte, unter Kontrolle zu halten. In diesem Zusammenhang traf Herakleios eine folgenschwere Entscheidung: Er begann, sich persönlich im militärischen Bereich zu betätigen. Während in der Forschung in der Regel seine späteren Kampagnen gegen die Perser, die mit der Rückgewinnung der Ostprovinzen endeten, im Fokus des Interesses stehen, wird im Folgenden deutlich, dass Herakleios bereits kurz nach seiner Krönung von etablierten monarchischen Verhaltensweisen abrückte, wiederholt die Hauptstadt verließ und sich persönlich an die Kriegsschauplätze begab.

Zwei gewaltsame Machtwechsel in weniger als einem Jahrzehnt hatten Hauptstadt und Reich destabilisiert. Nachdem sich das Kräftemessen der römischen und persischen Heere an der Ostgrenze über Jahre hinweg in der Waage gehalten hatte, zogen die Kämpfe in Ägypten, die mit der Revolte der Herakleioi einhergingen, wichtige Kräfte von der Front ab und schwächten die römische Verteidigung. Die Perser spielten ihren Vorteil aus: 609 eroberten Chosroes' Truppen den wichtigen Stützpunkt Edessa, im August 610 gelang die Überquerung des Euphrats. Die Lage verschärfte sich, als erneut Unruhen im römischen Heer ausbrachen: Wie bereits 602/03, als der General Narses sich gegen Phokas aufgelehnt hatte, reagierte auch 610/11 ein in Syrien stationierter Kommandeur mit Befehlsverweigerung auf den Machtwechsel in Konstantinopel: Komentiolos, Magister militum per Orientem und Bruder des gestürzten Phokas. $^{56}$

Die Revolten des Narses und Komentiolos unterscheiden sich von den militärischen Unruhen, die vor allem während der Regierung des Maurikios verstärkt aufgetreten waren und dessen Sturz mitbedingt hatten, insofern, als sie nicht in Folge unpopulärer kaiserlicher Entscheidungen (Soldkürzungen etc.) ausbrachen; stattdessen richteten sie sich gegen einen als inakzeptabel empfundenen Machtwechsel in Konstantinopel. ${ }^{57}$ Zumindest im Falle des Narses wird deutlich, dass er sich in seinem Handeln auf das gestützte Kaiserhauses - bzw. auf Theodosios als angeblich Überlebenden - berief; ${ }^{58}$ ähnliches wird man auch im Falle des Komentiolos vermuten können, auch wenn die Vita des Theodor von Sykeon als einzige Quelle dies nicht explizit macht. ${ }^{59}$ Für Komentiolos war die Revolte indes auch eine Flucht nach vorne,

56 Vit. Theod. Syk. 153; dazu Kaegi 1973, 312-316 und ders. 1981, 141-144; PLRE IIIA, Comentiolus 2 (326).

57 Laut Kaegi 1981, 139, 143 etablierte sich im Syrien-Heer im frühen 7. Jahrhundert eine Art „,conservative force”, die mit entschiedener Ablehnung auf die rasch aufeinander folgenden Machtwechsel in der Hauptstadt reagierte.

58 Dazu siehe oben S. 140.

59 Komentiolos' Revolte ist nur in Vit. Theod. Syk. 153 überliefert; die hauptstädtischen Quellen verschweigen sie. Dieser Befund lässt sich folgenermaßen erklären: Theodors Kloster in Sykeon war aufgrund seiner geographischen Nähe zu Ankyra direkt von der Anwesenheit des meuternden Heeres betroffen - die Gesandten aus Konstantinopel, die Komentiolos zum Aufgeben bewegen sollten, machten dort Station (siehe ebd.). Das Schweigen der hauptstädtischen Quellen könnte darauf hin- 
da ihm als Bruder des gestürzten Kaisers bewusst gewesen sein muss, dass seine Karriere, wenn nicht gar sein Leben unter dem neuen Regime verwirkt war; die ihm unterstellten Truppen bestanden zumindest teilweise aus dem ehemaligen Balkanheer, sodass eine gewisse Loyalität zu Phokas, der aus ihren Reihen stammte, nicht verwundert. ${ }^{60}$ Im Gegensatz zu Narses, der seine Truppen in Edessa gesammelt und keine Anstalten gemacht hatte, weiter gen Westen vorzurücken, führte Komentiolos das Syrienheer eigenmächtig zum Überwintern ins kleinasiatische Ankyra. Im Winter 610/11 stand also erneut ein aufständisches Heer nicht allzu weit von der Hauptstadt und gemahnte an die Geschehnisse des Herbstes 602, als der Druck des Balkanheeres, das auf Konstantinopel vorrückte, Maurikios' Sturz eingeleitet hatte. Obwohl immerhin der Bosporus die Soldaten unter Komentiolos' Befehl von Konstantinopel trennte, stellte die Revolte ein empfindliches Risiko für Herakleios' noch junge Herrschaft dar. ${ }^{61}$ Der Kaiser schickte mehrere Gesandtschaften, um mit Komentiolos zu verhandeln, der jedoch nicht auf die Friedensgesuche einging. Die Frage, ob Komentiolos tatsächlich plante, weiter Richtung Konstantinopel zu marschieren bzw. gar selbst einen Usurpationsversuch zu unternehmen, bleibt angesichts des jähen Endes der Revolte jedoch offen. ${ }^{62}$ Über den Hintergrund des Armeniers Justin, der Komentiolos des Nachts ermordete, ist weiter nichts bekannt. In jedem Fall hatte die Entwicklung in Kleinasien erneut gezeigt, wie dringend Herakleios den militärischen Sektor in den Griff bekommen musste. ${ }^{63}$ Die Meuterei des Syrien-Heeres zeitigte nicht nur innensondern auch außenpolitische Folgen: Im Laufe des Jahres 611 besetzten die Perser die syrischen Zentren Antiochia, Apamea und Emesa; unter Führung des Generals Shahin stieß ein persisches Kontingent gar über Armenien bis nach Kleinasien vor und besetzte Caesarea, die Hauptstadt Kappadokiens. ${ }^{64}$

weisen, dass die dem Herakleios wohlgesinnten Quellen diese unschöne Episode nach ihrer Beilegung lieber unerwähnt ließen.

60 Kaegi 1973, 313f. mit Anm. 13.

61 Siehe Kaegi 1973, 321f., der jedoch die Revolten des Narses und Komentiolos in einer Linie mit denen unter Maurikios, etwa der Monokarton-Revolte, liest.

62 Gemäß der Vit. Theod. Syk. 153, die bekanntlich erst nach Herakleios’ Tod vollendet wurde, kursierte zumindest das Gerücht, dass das Heer unter Komentiolos die Hauptstadt angreifen wolle (Festugière 1970, 128, Zeilen 49-52); dazu Kaegi 1973, 315.

63 Kaegi 1973, 317-319 verweist außerdem auf eine Reihe von Münzen, die darauf hindeuten, dass Herakleios' Herrschaft in Kleinasien zunächst alles andere als unumstritten war. Eine kleine Gruppe von Bronzemünzen (Folles) verzeichnet das 9. Regierungsjahr des Phokas; dieser wurde allerdings kurz vor dem Antritt seines 9. Jahres von Herakleios gestürzt. Anstatt diese Münzen der Prägestätten Antiochia und Kyzikos' als Fehlemissionen zu sehen, könnten sich in diesen auch die noch unklaren Machtverhältnisse des Winters 610/11 widerspiegeln. Kaegi bringt die These ein, dass lokale Prägestätten den Ausgang der Revolte des Komentiolos abwarteten, bevor sie schließlich auf die herakleischen Münztypen umstellten.

64 Zum Vorrücken der Perser siehe Flusin 1992 II, 70 - 83. Flusin diskutiert auch die komplizierte Quellenlage: Die verlässlichsten Informationen lassen sich den syrischen und auch armenischen Quellen entnehmen, während die griechischen - vor allem Theoph. Conf. - mit Vorsicht zu genießen sind. Zur Einnahme Caesareas siehe Vit. Theod. Syk. 153; Sebeos 33 - 34 (Thomson/Howard-Johnston I, 
Die Spannungen zwischen oströmischem Kaiser und hohen militärischen Funktionsträgern, die in Kapitel 2 bereits als einen maßgeblichen Faktor politischer Entscheidungsprozesse identifiziert wurden, lassen sich exemplarisch an den Entwicklungen des Sommers 612 verdeutlichen, als es im Feldlager bei Caesarea zum Showdown zwischen Herakleios und seinem ehemaligen Verbündeten Priskos kam. ${ }^{65}$ Nachdem Komentiolos ermordet worden war, fügten sich seine Truppen offenbar ohne weitere Probleme der hauptstädtischen Befehlsgewalt. Als neuen Kommandeur im Kampf gegen die Perser, die inzwischen Kleinasien bedrohten, bestellte Herakleios den Priskos. ${ }^{66}$ Priskos hatte einen wichtigen Beitrag zum Gelingen von Herakleios' Usurpation geleistet, indem er, schenkt man den Quellen Glauben, die Aufständischen über einen längeren Zeitraum hinweg mit Informationen über die Lage in Konstantinopel versorgte und sich im entscheidenden Moment, als Herakleios' Flotte im hauptstädtischen Hafen ankerte, mit den ihm untergebenen Exkubitoren gegen seinen Schwiegervater Phokas wandte. ${ }^{67}$ Herakleios zeigte sich erkenntlich, indem er Priskos nicht nur im Amt des Comes excubitorum beließ, ${ }^{68}$ sondern ihm darüber hinaus auch das Kommando als Magister militum per Orientem und damit die Befehlsgewalt über einen Großteil des römischen Feldheeres übertrug. Das Verhältnis zu dem erfahrenen Militär und Machtpolitiker Priskos, der in Konstantinopel als Patrikios über entscheidende Machtressourcen verfügte, stellte Herakleios allerdings vor ein Dilemma: Einerseits benötigte er gerade in der kritischen Anfangsphase seiner Herrschaft dessen Unterstützung - ihm blieb also kaum etwas anderes übrig, als Priskos' Machtbasis durch ein weiteres Kommando noch zu verbreitern; andererseits stellte Priskos, dessen Loyalität zum regierenden Kaiser sich bereits wiederholt als fragil erwiesen hatte, gerade aufgrund seiner Machtfülle für Herakleios ein schwer kalkulierbares Risiko dar.

Nachdem Priskos das Kommando gegen die Perser angetreten hatte, die im Laufe des Jahres 611 bis nach Kleinasien vorgedrungen waren, gelang es ihm, das vom persischen General Shahin befehligte Heer im kappadokischen Caesarea einzuschließen. Etwa ein Jahr dauerte die Belagerung an. Priskos' Chancen standen gut; angesichts der schlechten Versorgungslage der Perser ging man auf römischer Seite davon aus, dass ein Triumph nicht mehr allzu lange auf sich warten lassen würde. ${ }^{69}$ Doch es kam anders: Im Sommer des folgenden Jahres konnten die Perser unerwartet

64-66); Theoph. Conf. AM 6103 (De Boor 299); Mich. Syr. 11.1 (Chabot II, 400); Chron. 1234, 92 (Chabot I, 177f.); siehe Flusin 1992 II, 81-83.

65 Zu dieser Episode siehe Kaegi 1973, 325-328; ders. 1981, 145-147; ders. 2003, 68-71; Pfeilschifter 2013, 68-70; Raum 2019, 133f.,

66 Vit. Theod. Syk. 153; Nik. Brev. 2; ob dem Priskos tatsächlich das Amt des Magister militum per Orientem übertragen wurde, wird aus den Quellen nicht ganz deutlich; vgl. PLRE IIIB, Priscus 6 (10521057, hier 1057).

67 Siehe oben Kap. 3.2.

68 Vit. Theod. Syk. 153; zur späteren Absetzung des Priskos siehe Chron. Pasch. AD 612; Vit. Theod.

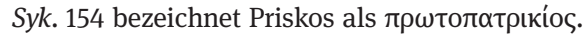

69 Zur Erwartung eines römischen Triumphes siehe Vit. Theod. Syk. 153. 
aus der Befestigung ausbrechen und sich, von den Römern ungehindert, auf heimatliches Gebiet durchschlagen. ${ }^{70}$

In diesem Zusammenhang traf Herakleios eine überraschende Entscheidung. Etwa eineinhalb Jahre nach seiner Krönung verließ er erstmals Konstantinopel und machte sich auf den Weg zu den römischen Truppen nach Caesarea - laut Nikephoros, um sich mit Priskos zu beraten, der sich dort weiterhin aufhielt. ${ }^{71}$ Der Zeitpunkt erweist sich als bewusst gewählt: Nach dem Misserfolg gegen die Perser war Priskos' Stellung angekratzt; Herakleios nutzte seinerseits die Gelegenheit, um die Machtfülle des erfahrenen Generals einzuhegen und die kaiserliche Autorität über den militärischen Sektor zu betonen. Im Feldlager kam es allerdings zum Eklat: Während die Soldaten Herakleios' Präsenz sicherlich begrüßten, machte Priskos deutlich, dass ihm das kaiserliche Eindringen in seinen Zuständigkeitsbereich überhaupt nicht gefiel. Seine Reaktion auf den hohen Besuch, wie sie Nikephoros' Breviarium überliefert, hätte deutlicher kaum sein können. Der General begegnete Herakleios geradezu mit Respektlosigkeit; er entzog sich dessen Gesprächsgesuchen, indem er sich krankstellte, und lästerte gar öffentlich gegen den Kaiser: „Aber der andere [i.e. Priskos] sagte, wie im Scherz, dass es sich für den Kaiser nicht gebühre, den Palast zu verlassen und unter den weit entfernten Streitkräften zu verweilen. “72 Das Zitat - egal ob man es als authentisch wertet oder nicht - trifft die strukturellen Charakteristika oströmischer Monarchie an der Wende vom 6. zum 7. Jahrhundert mit einer Präzision und gleichzeitig Abstraktion auf den Punkt, die man in den Quellen meist vergeblich sucht. ${ }^{73}$ Wie bereits im Zusammenhang mit Maurikios' Versuchen, sich einige Jahrzehnte zuvor

70 Zur Belagerung Caesareas durch Priskos und dem Ausbruch der Perser siehe Vit. Theod. Syk. 153; Sebeos 34 (Thomson/Howard-Johnston I, 66): mit Angabe der Dauer (ein Jahr) und Zeitpunkt des Ausbruchs (offenbar Frühsommer); siehe dazu Kaegi 1973, 324- 328 und Flusin 1992 II, 81-83.

71 Nik. Brev. 2. Dies mag in der Tat der offiziell verlautbarte Anlass gewesen sein (vgl. Vit. Theod. Syk. 154). Die Belagerung Caesareas wird bei Nikephoros allerdings nicht erwähnt. Keine der Quellen macht explizit, dass Herakleios sich erst nach dem Ausbruch der Perser nach Caesarea begab; dies ist allerdings der plausibelste Ablauf und erklärt auch, warum Nikephoros den Kontext des Besuches nicht erwähnt - die Perser waren bei Herakleios’ Ankunft bereits über alle Berge (im wahrsten Sinne des Wortes). Vit. Theod. Syk. thematisiert Herakleios' Abstecher nach Caesarea (154) nach der Belagerung der Stadt durch Priskos (153); siehe Kaegi 1973, 325 zur Chronologie. Folgt man dem Bericht der Vit. Theod. Syk. 154, könnte Herakleios' Aufbruch gar ein recht spontaner gewesen sein - also in direkter Reaktion auf das Eintreffen der Nachricht vom Ausbruch der Perser. Die Vita schildert nämlich, dass Herakleios und Sergios den Heiligen Theodor nach Konstantinopel eingeladen hatten; als dieser in der Hauptstadt eintraf, habe sich herausgestellt, dass Herakleios vor kurzem nach Caesarea aufgebrochen war. Wäre Herakleios' Besuch länger geplant gewesen, ist davon auszugehen, dass Theodor, dessen Kloster an einem der wichtigsten Postrouten durch Kleinasien lag, davon in Kenntnis gesetzt wurde und seine Reise nach Konstantinopel angepasst hätte; siehe dazu Kaegi 1973, 327. Zur absoluten Chronologie siehe unten S. 155 Anm. 75.

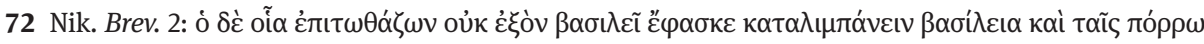

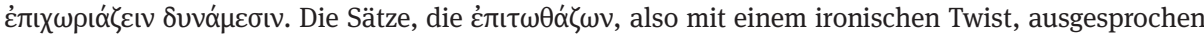
werden, treffen die Gemengelagen, auf die sie sich beziehen, ja bekanntlich oft besonders gut.

73 Vgl. Pfeilschifter 2013, 69. 
persönlich als Feldherr zu engagieren, ${ }^{74}$ so tritt auch hier wieder zu Tage, wie fest die Bindungen waren, die die oströmischen Kaiser an das hauptstädtische Umfeld ketteten. Priskos interpretierte Herakleios' Vorstoß ganz richtig: Er sah sich durch dessen Besuch in seinem Kompetenzbereich, dem militärischen Sektor, gestört; in Reaktion darauf versuchte er, den Kaiser mit Verweis auf vorherrschende Verhaltenserwartungen in dessen Schranken zu verweisen, räumlich umrissen durch den hauptstädtischen Palast.

Ohne die genauen Abläufe des Aufeinandertreffens zwischen Priskos und Herakleios im Feldlager bei Caesarea im Detail nachvollziehen zu können, lässt sich festhalten, dass der Kaiser letztendlich am längeren Hebel saß: Er beorderte bei seinem eigenen Abzug aus Caesarea auch den General in die Hauptstadt zurück; diesem blieb offenbar nichts anderes übrig, als sich zu fügen. ${ }^{75}$ Doch das Ringen zwischen Kaiser und Feldherr war damit noch nicht zu Ende; die letzte Runde wurde nach beider Rückkehr nach Konstantinopel im Herbst 612 eingeläutet. Erneut ist es Nikephoros, der den ausführlichsten Bericht liefert: Unter dem Vorwand, ihn zum Paten seines neugeborenen Sohnes Herakleios Konstantin zu machen, soll Herakleios Priskos in den Palast gebeten haben; dort stellte er ihn vor dem Patriarchen, den Mitgliedern des Senates und Vertretern des Volkes bloß, enthob ihn seiner Ämter und ließ ihn vom Patriarchen zum Kleriker weihen. ${ }^{76}$

Der von Nikephoros dargelegte Ablauf erscheint plausibel. Die Aussicht, Priskos zum Paten des männlichen Erstgeborenen des Kaisers zu machen, entspricht Mustern,

74 Dazu siehe oben S. $74 \mathrm{f}$.

75 Eine gemeinsame Rückkehr legt Nik. Brev. 2 nahe; die Rückkehr erfolgte laut Nikephoros, da Herakleios ein Sohn geboren worden war und sein Cousin Niketas in Konstantinopel eintraf. Diese Verbindung ist allerdings unwahrscheinlich, wenn man davon ausgeht, dass Herakleios sich erst nach dem Ausbruch der Perser in Caesarea einfand und der Ausbruch sich im (Früh-)Sommer 612 ereignete denn Herakleios Konstantin wurde bereits am 3. Mai 612 geboren (Chron. Pasch. AD 612; Theoph. Conf AM 6103 [300]). Vit. Theod. Syk. 154 legt außerdem nahe, dass sich Niketas bereits in Konstantinopel befand, als Herakleios in Caesarea weilte - anstatt auf Herakleios zu treffen, trat der Heilige in Konstantinopel mit Niketas in Kontakt und heilte diesen von einer Krankheit; als Herakleios sich der Stadt näherte, ritt Niketas ihm entgegen; siehe dazu Kaegi 1973, 325 f. Folgende Chronologie lässt sich für die Caesarea-Episode meiner Ansicht nach plausibel rekonstruieren. Sommer 611: Perser werden in Caesarea eingeschlossen; (Früh-)Sommer 612: Ausbruch der Perser nach etwa einem Jahr (siehe Sebeos 34 [Thomson/Howard-Johnston I, 66]); kurz darauf Ankunft des Herakleios; Spätsommer/Frühherbst 612: Rückkehr des Herakleios (und Priskos) nach Konstantinopel. Der Zeitpunkt der Rückkehr wird in den Quellen nicht spezifiziert; am 4. Okt. 612 wurde allerdings Epiphania, Herakleios' erstgeborene Tochter, gemäß Chron. Pasch. AD 612 in Konstantinopel zur Augusta gekrönt. Obwohl Chron. Pasch. Herakleios' Teilnahme am Krönungsritual nicht explizit macht, ist doch davon auszugehen, dass der Kaiser auf seine Anwesenheit bei einem derart wichtigen öffentlichen Ereignis Wert legte (den Termin konnte er ja selbst festlegen). Das Chron. Pasch. gibt außerdem an, Priskos sei am 5. Dez. seines Amtes als Comes excubitorum entkleidet worden (vgl. Nik. Brev. 2); allerspätestens dann waren also beide wieder aus Caesarea zurück.

76 Nik. Brev. 2; Priskos' Absetzung und seine Exilierung ins Kloster werden durch das zeitgenössische Chron. Pasch. AD 612 bestätigt, das allerdings zum Kontext (Herakleios’ Abstecher nach Caesarea und die Auseinandersetzung zwischen den beiden Männern) schweigt. 
die in Kapitel 2 als typisch für die oströmische Monarchie herausgearbeitet wurden: Herausragende Militärs konnten ihr soziales Prestige nutzen, um sich mit dem Kaiserhaus zu verbinden und dadurch ihren Einfluss noch zu vergrößern. Phokas hatte Prikos bereits seine einzige Tochter zu Frau gegeben; Herakleios stellte dem mächtigen General nun, trotz bestehender Unstimmigkeiten, in Form der Patenschaft eine Verbindung mit dem neuen Kaiserhaus in Aussicht. ${ }^{77}$ Doch während Herakleios im Feldlager, dem Kompetenzbereich des Generals, offenbar nicht viel gegen Priskos hatte ausrichten können, standen ihm nun, zurück im hauptstädtischen Umfeld, mehr Möglichkeiten zur Verfügung; er konnte sich des Störfaktors, als welcher Priskos sich erwiesen hatte, entledigen. Priskos' Absetzung, die Ermächtigung des Kaisers gegenüber dem militärischen Funktionsträger, fand im Palast vor Vertretern der Gruppen statt, auf deren Akzeptanz Herakleios angewiesen war. Durch ihre Anwesenheit sanktionierten Senat und Vertreter des Volkes diesen Akt; Herakleios setzte ein deutliches Zeichen kaiserlicher Autorität. An Priskos' Stelle übertrug er das Amt des Comes excubitorum seinem Cousin Niketas. ${ }^{78}$ Als Oberbefehlshaber über das Heer im Osten ernannte der Kaiser seinen Bruder Theodor; außerdem rehabilitierte er Philippikos, den Schwager des Maurikios, der nach erfolgreicher militärischer Karriere von Phokas exiliert worden war. ${ }^{79}$

Nach der Konfrontation im Palast stellte Herakleios sich Priskos' Privatgarden, den Bukellariern, und verkündete, diese unter guten Konditionen in die kaiserlichen Kontingente einzugliedern: Die Soldaten ihrerseits begrüßten den neuen Dienstherren mit Akklamationen. ${ }^{80}$ Bukellarier, zahlenmäßig starke Privattruppen, die auch innerhalb der Stadtmauern Konstantinopels agierten und nicht direkt der kaiserlichen Befehlsgewalt unterstanden, konnten politischen Akteuren als Druckmittel gegenüber dem Monarchen dienen. Als Priskos sich etwa im Oktober 610 gegen Phokas positioniert hatte, hatte er nicht nur die Exkubitoren, sondern auch seine Bukellarier zusammengezogen und mit diesen Truppen in die gewaltsamen Auseinandersetzungen eingegriffen, die in den Häfen entbrannt waren. ${ }^{81}$ Indem Herakleios die Privatgarde des Priskos nun an seine Person band, neutralisierte er deren widerständiges Potential.

Mit Prikos’ Absetzung hatte Herakleios einen ernstzunehmenden Konkurrenten aus dem Weg geschafft; doch in Hinblick auf die Sicherung des militärischen Sektors

77 Die Taufe des Herakleios Konstantin erfolgte in der Tat kurz darauf (Nik. Brev. 5).

78 Chron. Pasch. AD 612 gibt das Datum von Priskos’ Absetzung den 5. Dez. 612 an. Vit. Theod. Syk. 154 hingegen adressiert Niketas bereits mit dem Titel des Comes excubitorum, als Herakleios sich noch mit Priskos in Caesarea befindet; dabei handelt es sich aber aller Wahrscheinlichkeit nach um eine Ungenauigkeit: die Übertragung des Amtes an Niketas kann plausibel nur nach der Absetzung des Priskos stattgefunden haben, wie sie in Chron. Pasch. und Nik. Brev. 2 konsistent geschildert wird; siehe dazu Kaegi 1973, 327 f. Zu Niketas vgl. außerdem PLRE IIIB, Niketas 7 (940 - 943) und Rapp 2004.

79 PLRE IIIB, Theodorus 163 (1277-1279); PLRE IIIB, Philippicus 3 (1022-1026). Vgl. Kaegi 2003, 70 f. zu den Ämterbesetzungen.

80 Nik. Brev. 2.

81 Zu den Bukellariern siehe oben S. 43-45; zu Priskos’ Eingreifen in die Kämpfe siehe oben S. 101103. 
reichte ihm dies offenbar nicht aus. Kein Jahr, nachdem er aus Caesarea zurückgekehrt war, verließ Herakleios erneut die Hauptstadt, um diesmal noch weiter nach Osten vorzudringen: Im Frühjahr 613 brach er gemeinsam mit seinem Bruder Theodor gen Syrien auf, wo sich die Perser bereits seit mehreren Jahren festgesetzt hatten. ${ }^{82}$ Doch es zeigte sich rasch, dass das römische Heer der persischen Übermacht kaum etwas entgegenzusetzen hatte. Eine Schlacht nahe Antiochia endete für die Römer in einer desaströsen Niederlage. Auch bei den Kilikischen Pforten unterlagen die kaiserlichen Truppen, sodass die Perser Tarsos einnehmen konnten. Nachdem die römische Verteidigung Syriens zusammengebrochen war, stand Chosroes' Truppen auch der Weg nach Palästina offen. ${ }^{83}$ Die Armenische Geschichte des Sebeos als einzige Evidenz für die Syrien-Episode gibt keinen Hinweis auf Herakleios' weiteren Verbleib; es ist allerdings davon auszugehen, dass dieser sich unter dem Eindruck der Niederlage auf den Rückweg nach Konstantinopel machte.

Im Zusammenhang mit dieser Kampagne ist zunächst eine Beobachtung zu machen, die Herakleios' Umgang mit Heiligen Männern betrifft. Die Vita des Theodor von Sykeon berichtet, wie Herakleios seine Reise von Konstantinopel nach Syrien unterbrach, um dem Heiligen während der Fastenzeit in dessen Kloster einen Besuch abzustatten. Nachdem die beiden Männer gemeinsam in der Kirche gebetet hatten, drängte Herakleios jedoch auf einen raschen Aufbruch; weder Theodors Geschenke habe Herakleios annehmen wollen noch dessen Einladung zum gemeinsamen Essen; stattdessen vertröstete er den Heiligen mit dem Versprechen eines erneuten Besuches auf dem Rückweg von Syrien. Enttäuscht von einer derart harschen Behandlung habe Theodor nicht nur Herakleios' Niederlage gegen die Perser prophezeit, sondern darüber hinaus festgestellt, dass diese durch die Annahme der gesegneten Geschenke hätte verhindert werden können. ${ }^{84}$ Theodor verstarb am 22. April 613, also noch bevor Herakleios Sykeon auf seinem Rückweg von Syrien passierte.

Diese Episode befremdet: Warum schlug Herakleios Theodors Angebote aus? Walter E. Kaegi meint, dass der Kaiser gegenüber dem Heiligen Vorbehalte gehegt habe, da dieser eine enge Verbindung zur Familie seines Vorgängers Phokas pflegte. ${ }^{85}$ Eine derartige Deutung überzeugt allerdings nicht, da verschiedene Gelegenheiten überliefert sind, bei denen Herakleios sich dezidiert um ein Nahverhältnis mit Theodor bemühte: Er ehrte ihn nicht nur durch ein privates Treffen im kaiserlichen Palast kurz nach seiner Rückkehr aus Caesarea, ${ }^{86}$ sondern ließ auch Theodors Überreste nach dessen Tod in die Hauptstadt überführen; ein anlässlich dieser Translation

82 Laut Vit. Theod. Syk. 166 begleitete ihn Niketas, laut Sebeos 34 (Thomson/Howard-Johnston I, 68) sein Bruder Theodosios.

83 Sebeos 34 (Thomson/Howard-Johnston I, 68); zu der Kampagne von 613 siehe Stratos 1968, 105107; Kaegi 1973, 328f. und ders. 2003, 75-77; außerdem Greatrex/Lieu 2002, $189 \mathrm{f}$.

84 Vit. Theod. Syk. 166. Hierbei handelt es sich um ein für hagiographische Literatur typisches Vaticinium ex eventu; siehe auch Van Ginkel 2002, 231.

85 Kaegi 2003, 76.

86 Vit. Theod. Syk. 155. 
verfasstes Enkomium schildert, wie der Kaiser den Reliquien persönlich einen gebührenden Empfang bereitete. ${ }^{87}$ Wie bereits sein Vorgänger versuchte also auch Herakleios, von der spirituellen Autorität des Heiligen Theodor zu profitieren.

Der Gehalt dieser Episode wird deutlich, wenn man die narrative Strategie der Vita einkalkuliert. ${ }^{88}$ Ziel einer jeden Hagiographie war es, die Heiligkeit und spirituelle Wirkmächtigkeit des Protagonisten unter Beweis zu stellen; dies konnte durch die Aneinanderreihung von Wundererzählungen geschehen, durch die Zuschreibung von Prophezeiungen wie der obigen (Vaticinia ex eventu), die sich dann selbstverständlich bewahrheiten, aber auch, indem Ereigniszusammenhänge mit einer spezifischen Deutung belegt bzw. gar zu einem gewissen Grad in ihrem Wahrheitsgehalt gebeugt wurden. Das Grundgerüst der Geschehnisse des Frühjahrs 613 ist Folgendes: Herakleios besuchte Theodor auf seinem Weg nach Syrien; dort erlitt er eine Niederlage und kehrte nach Konstantinopel zurück. Dass Herakleios direkt nach seinem Besuch in Sykeon eine Niederlage erlitt, spricht - denkt man entlang hagiographischer Erzählstrategie - nicht unbedingt für die spirituelle Wirkmächtigkeit des Heiligen. Um die ,Verantwortung“ von Theodor abzuwälzen, konstruierte der Autor der Vita - so die These - eine alternative Erzählung, in der Herakleios dessen Segensgaben mutwillig zurückwies und damit seine Niederlage einleitete. In Herakleios' Ablehnung der Speisung könnte man indes einen wahren Kern vermuten. Die mit dem Kaiser reisenden Soldaten mussten auf dem Weg nach Syrien versorgt werden, was zum größten Teil durch lokale Kapazitäten geleistet wurde; der Kaiser könnte den Heiligen und dessen Kloster als Zeichen der Wertschätzung von der Pflicht der Truppenversorgung entbunden haben. Herakleios' Entgegenkommen wurde - folgt man der These Jahrzehnte später durch den Hagiographen als Zurückweisung umgedeutet.

Über das Treffen mit Theodor hinaus gibt das kaiserliche Engagement in Syrien allerdings auch Anlass für weitere Überlegungen, da es die Risiken von Herakleios' persönlichem Engagement als Heerführer verdeutlicht. Während der Aufenthalt des Kaisers bei den römischen Truppen in Caesarea 612 nicht - soweit rekonstruierbar mit Kampfhandlungen einhergegangen war, stellte sich das römische Heer unter Herakleios' Befehl im darauffolgenden Jahr den persischen Aggressoren und wurde dabei zwei Mal in Folge geschlagen. Wie nah Herakleios den konkreten Kampfhandlungen in Syrien kam, tut für die hier gewählte Perspektive nichts zur Sache. Als wichtiger erweist sich folgender Umstand: Indem er im Gegensatz zu seinen Vorgängern wieder persönlich als Heerführer fungierte, konnte Herakleios in weit höherem Maße als in den Jahrhunderten der sesshaften Kaiser in der Wahrnehmung der Öffentlichkeit für die Niederlage der römischen Truppen verantwortlich gemacht werden.

Darüber, wie das Syrien-Debakel in Konstantinopel aufgenommen wurde, schweigen die Quellen; in hauptstädtischen Texten findet die Episode überhaupt

87 Zum Enkomium siehe Kirch 1901.

88 Ich verdanke diese Idee einem Gespräch mit Efthymios Rizos in Oxford. 
keine Erwähnung. ${ }^{89}$ Insofern lassen sich dahingehend nur abstrakte Überlegungen anstellen. Felix K. Maier hat in seiner Habilitationsschrift den Prozess nachvollzogen, der in einer hauptstädtischen Konfiguration von Monarchie mündete und damit das politische System Ostroms über zwei Jahrhunderte maßgeblich prägte. Entlang seines Paradigmas des Imperator-Dilemmas ${ }^{90}$ hat er einen Sachverhalt, der in der Forschung bereits wiederholt beobachtet wurde, in seiner Entwicklungslogik beleuchtet: Über Jahrhunderte hinweg hatte die Idee eines Basileus polemikos - eines Kaisers, der sich persönlich auf dem Schlachtfeld engagierte und dadurch die Propagatio imperii vorantrieb - die Herrschaftspraxis wie die Erwartungen an die römischen Kaiser geprägt. Dieses Ideal konnte im Laufe des vierten Jahrhunderts allerdings nicht mehr aufrechterhalten werden, als erhöhter außenpolitischer Druck und innerrömische Zerwürfnisse aggressive Kriegsführung zunehmend riskant machten. ${ }^{91}$ Um politischer Instabilität als Folge militärischer Niederlagen vorzubeugen, verlegten sich die Kaiser vermehrt auf diplomatische Mittel - und enttäuschten damit die an sie gerichteten Verhaltenserwartungen. Das Sesshaftwerden in Konstantinopel - ein Prozess, der nach Maier bereits unter Theodosios I. eingeleitet wurde ${ }^{92}$ - bot den Kaisern neue Positionierungsmöglichkeiten jenseits von persönlichem militärischem Engagement; als ewige Sieger repräsentiert, konnten sich die nichtkriegerischen Kaiser zu einem gewissen Grad gegen die Konsequenzen militärischer Niederlagen immunisieren. ${ }^{93}$ Mit der hauptstädtischen Konfiguration von Monarchie ging, so der Konsens der Forschung, eine Stabilisierung kaiserlicher Herrschaft einher. ${ }^{94}$ Nach zwei gewaltsa-

89 Die hauptstädtischen Quellen, die allesamt nach Herakleios' Sieg über die Perser 628 entstanden sind, können es sich leisten, diese unrühmliche Episode der frühen Regierungsjahre einfach zu verschweigen. Die Frage, wie eine römische Niederlage wahrgenommen wurde und wie der Kaiser diese zu bewältigen suchte, wird an späterer Stelle in Zusammenhang mit der Schlacht am Yarmuk 636 genauer diskutiert. Allgemein zur Wahrnehmung und Bewältigung militärischer Niederlagen vgl. Stoll 2016. 90 Eine Definition findet sich in Maier 2019, 7.

91 Die Kaiser Julian und Valens fielen im Kampf: Ersterer während des Perserfeldzuges 363, Letzterer bei der Schlacht von Adrianopel 378. Zu Umgestaltung politischer Hierarchien aus prekären Situationen (Niederlagen) heraus siehe Maier 2019, $339 \mathrm{f}$.

92 Maier 2019, zusammenfassend 451-462; vgl. auch oben S. $31 \mathrm{f}$.

93 Zur spätantiken Siegesideologie siehe vor allem McCormick 1986. Es ist an dieser Stelle festzuhalten, dass die militärische Performance des römischen Heeres durchaus auch Einfluss auf die sesshaften Kaiser zeitigen konnte: Einerseits dienten errungene Siege dem kaiserlichen Prestige (zur Aneignung militärischer Siege durch die sesshaften Kaiser siehe oben S. 64-66); andererseits gingen auch Niederlagen nicht gänzlich an ihnen vorbei. Der Kaiser wurde weiterhin als Garant für das Wohl des Reiches verstanden; in einem christlichen Deutungsrahmen konnten Extremzustände wie etwa militärische Niederlagen und deren Folgen für die Bevölkerung den Schluss nach sich ziehen, der Kaiser habe die Gunst Gottes verspielt und damit Unglück übers römische Reich gebracht - und eine derartige Wahrnehmung konnte wiederum Akzeptanzverlust nach sich ziehen. Militärische Niederlagen konnten außerdem auch ganz konkrete Auswirkungen auf die politische Hierarchie Konstantinopels zeitigen: Nachdem die Perser 574 die Grenzfestung Dara eingenommen hatten, konnte Justin II. sich nicht mehr an der Macht halten und musste - folgt man der oben S. 69f. dargelegten Argumentation - dem Tiberios das Feld räumen.

94 Dazu siehe oben S. $27 \mathrm{f}$. 
men Machtwechseln in Folge, die im Militär ihren Ursprung genommen hatten, schien das Verweilen in Konstantinopel allerdings im frühen 7. Jahrhundert für den Kaiser keine praktikable Option mehr - vor allem angesichts eines erneut entflammten Konfliktes mit den Persern; zu groß war die Gefahr einer erneuten Aggression von Seiten der Truppen bzw. exponierter Feldherren. Mit seiner Remilitarisierung - indem er erneut als Basileus polemikos das Kommando über die Truppen übernahm - versuchte Herakleios, eine Antwort auf diese Entwicklung zu geben. Die Immunisierung gegen militärische Niederlagen, die die sesshaften Kaiser zu einem gewissen Grad hatten aufrecht erhalten können, setzte er dabei allerdings aufs Spiel; die Imago des ewigen Siegers war mit der Realität eines in der Schlacht gegen die Perser unterlegenen Kaisers schwer vereinbar.

Herakleios war nach seiner erfolgreichen Usurpation darum bemüht, die kaiserliche Autorität über den militärischen Sektor wiederherzustellen und damit einem erneuten Machtwechsel - bzw. dem Versuch eines militärischen Funktionsträgers, einen solchen einzuleiten - vorzubeugen. Der desaströse Ausgang der Kampagne von 613 machte allerdings die Risiken allzu deutlich, die für den Kaiser mit persönlicher Kriegführung einhergingen: Eine Niederlage hatte das Potential, die prekäre Akzeptanzgrundlage in der Hauptstadt weiter zu schwächen. Soweit den Quellen zu entnehmen, gab es in Folge der Syrien-Episode keinen ernstzunehmenden Versuch, Herakleios' Herrschaft etwa durch erneute Meutereien oder gar eine Usurpation in Frage zu stellen. Doch der Kaiser ruderte dennoch zurück: Vorerst sah er von einem erneuten Engagement als Heerführer ab und konzentrierte sich auf Konstantinopel. Es sollte beinahe ein Jahrzehnt dauern, bis er die Hauptstadt erneut verließ.

\subsection{Eine Dynastie im Entstehen}

Während der Ansturm der Perser im Osten des Reiches kaum unter Kontrolle gebracht werden konnte, begann Herakleios seine Basis in bzw. von Konstantinopel aus zu sichern und setze dabei besonders in dem Bereich der Familienpolitik bemerkenswerte Akzente. Wie seine Vorgänger war auch er nach seiner Erhebung darum bemüht, ein durch klare Loyalitätsbeziehungen konstituiertes Umfeld aufzubauen und die wichtigsten (vor allem militärischen) Ämter mit Vertrauten, wenn nicht gar Verwandten, zu besetzen. Nach Priskos' Entmachtung rückte - wie oben geschildert Herakleios' Cousin, der Patrikios Niketas, in das Amt des Comes excubitorum nach; ${ }^{95}$ seine Loyalität hatte Niketas bereits vor dem Machtwechsel von 610 unter Beweis gestellt, als er im Auftrag der Herakleioi Ägypten sicherte. ${ }^{96}$ Niketas war allerdings nicht nur in militärischer Mission aktiv: Quellen belegen, dass er in Ägypten auch

95 Chron. Pasch. AD 612.

96 Dazu siehe oben S. 95. 
administrative Autorität genoss und gar in religiöse Angelegenheiten eingriff. ${ }^{97}$ Über die Vergabe zentraler Ämter hinaus zeigte Herakleios sich bemüht, die Bande zu seinem Cousin weiter zu stärken, indem er diesen zum Paten seines erstgeborenen Sohnes Herakleios Konstantin machte. ${ }^{98}$ Anlässlich der Taufe wurde Herakleios Konstantin außerdem mit Niketas’ Tochter Gregoria verlobt; die Ehe wurde im Jahr 630 geschlossen. ${ }^{99}$ Selbst im Stadtbild Konstantinopels fand das enge Verhältnis der beiden Cousins Ausdruck: Auf einem der hauptstädtischen Fora ließ Herakleios dem Niketas eine auf Säulen thronende Reiterstatue errichten - eine außergewöhnliche Ehrung, die in derartiger Form in der Regel dem Kaiser vorbehalten war. ${ }^{100}$ Den Oberbefehl über die im Osten stationierten Truppen, der anfänglich weiterhin von Priskos vereinnahmt worden war, übertrug Herakleios an seinen Bruder Theodor, der bereits das zivile Amt des Curopalates innehatte - ein weiteres Beispiel dafür, dass militärische und zivile Kompetenzen sich nach einer Phase der formal strikteren Trennung nun wieder zunehmend $\mathrm{zu}$ vermischen begannen. ${ }^{101}$ Außerdem rehabilitierte Herakleios den Philippikos, einen erfahrenen Militär und Schwager des Maurikios, der von Phokas exiliert worden war. ${ }^{102}$ Dass Herakleios' Netzwerk auch über den militärischen Sektor bzw. das direkte hauptstädtische Umfeld hinausging, verdeutlicht das Beispiel des Johannes, Patriarch von Alexandria: Als Sohn einer einflussreichen zypriotischen Familie wurde Johannes ohne klerikale Vorgeschichte 609/610 auf Niketas' Drängen hin zum Patriarchen geweiht. Als die persische Invasion Flüchtlinge

97 Siehe PLRE IIIB, Niketas 7 (940 - 943). In der Regel geht die Forschung davon aus, dass Niketas das Amt des Praefectus augustalis von Ägypten besetzte und als solcher auch an der Schlichtung von Auseinandersetzungen zwischen den miaphysitischen Gemeinden von Alexandria und Antiochia beteiligt war (dazu explizit Olster 1985); siehe etwa Rapp 2004, 124 und Kaegi 2003, 53.

98 Siehe Rapp 2004, 132f.; die Quelle, auf die Rapp sich bezieht (Nik. Brev. 5), erwähnt an keiner Stelle explizit, dass Niketas als Pate des Jungen fungierte. Dass es sich so verhielt, ist allerdings durchaus plausibel - auch vor dem Hintergrund, dass zuvor dem Priskos die Patenschaft versprochen worden war (Nik. Brev. 2); nach Priskos’ Absetzung wäre Niketas demnach nicht nur ins Amt des Comes excubitorum nachgerückt, sondern auch als Pate des designierten Thronfolgers. Rapp schlägt außerdem vor, dass gemeinsam mit Niketas auch Johannes, der Patriarch von Alexandria, als Pate des Herakleios Konstantin fungierte und sich demnach 612/613 auch in Konstantinopel aufhielt (Rapp 2004, 131-133); dies ist allerdings anhand der erhaltenen Quellen nicht eindeutig belegbar.

99 Nik. Brev. 5 (Verlobung); Nik. Brev. 17 (Eheschließung).

100 Nik. Brev. 5; vgl. Mango 1990, 175 f.; der Reiterstatue sind wohl zwei Epigramme aus der Anthologia

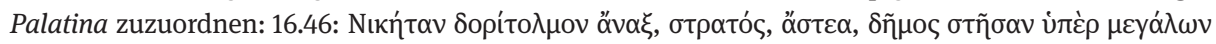

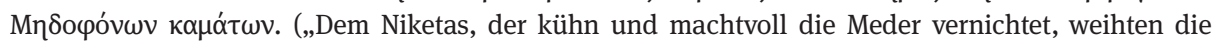

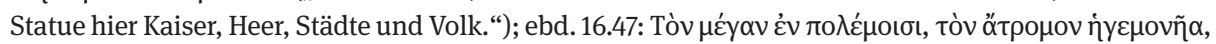

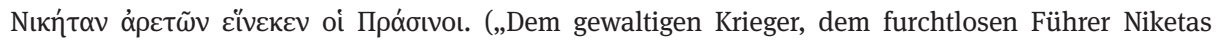
weihte, der Größe zum Ruhm, dieses die Grüne Partei.“). Auf welchen Sieg über die Perser sich das erste Epigramm bezieht, bleibt unklar.

101 PLRE IIIB, Theodorus 163 (1277-1279); vgl. zu militärischen und zivilen Karrieren S. $39 \mathrm{f}$.

$102 \mathrm{Zu}$ Philippikos siehe Sebeos 34 (Thomson/Howard-Johnston I, 67); Nik. Brev. 2; vor dessen Bestellung zum Feldherrn hatte Herakleios den Philippikos bereits im Zusammenhang mit der Revolte des Komentiolos als Boten mit einem Friedensangebot nach Ankyra geschickt; siehe Vit. Theod. Syk. 152; PLRE IIIB, Philippicus 3 (1022-1026); siehe Kaegi 2003, 70 f. zu den Ämterbesetzungen. 
aus der Levante nach Ägypten trieb, übernahm Johannes an Niketas’ Seite auch administrative Aufgaben. ${ }^{103}$

Die kaiserlichen Bemühungen, die eigene Familie zu stärken, äußerten sich über besagte Ämterbesetzungen hinaus ganz besonders darin, dass Herakleios seine Kinder in außerordentlichem Maße in den Fokus der Öffentlichkeit rückte. Seine Frau Eudokia gebar am 7. Juli 611 eine Tochter, Epiphania, und am 3. Mai 612 einen Sohn, Herakleios den Jüngeren, der den Beinamen „Neuer Konstantin“ trug. Nach dem frühen Tod Eudokias im August 612 wurde ihre Tochter Epiphania am 4. Oktober desselben Jahres in der Stephans-Kapelle im Palast zur Augusta gekrönt. ${ }^{104} \mathrm{Am}$ 22. Januar 613 schließlich krönte Herakleios ebendort auch seinen knapp einjährigen Sohn Herakleios Konstantin zum Augustus. Der Krönung war die Taufe des Jungen im Palast vorausgegangen. ${ }^{105}$

Dass römische Kaiser ihre leiblichen Söhne zum Augustus erhoben und damit die Nachfolge indizierten, war durchaus gängige Praxis. Theodosios I. verfuhr derart mit seinen beiden Söhnen Arkadios und Honorios; Arkadios krönte seinen Sohn Theodosios II. und auch Maurikios, der nach Arkadios erstmals wieder einen Sohn hatte, welcher das frühe Kindesalter überlebte, verfuhr dementsprechend. ${ }^{106}$ Dynastische Bindungen wogen in Hinblick auf monarchische Sukzession weiterhin schwer. ${ }^{107}$ Doch selbst vor diesem Hintergrund erfolgte die Designation in Herakleios' Fall bemerkenswert früh - Herakleios Konstantin war bei seiner Krönung noch nicht einmal ein Jahr alt. In Bezug auf die Designation von Maurikios' Sohn Theodosios wurde bereits herausgearbeitet, dass diese zu einem Zeitpunkt erfolgte, als der Kaiser sich dazu genötigt sah, seine Herrschaft abzusichern: Unruhen in Persien ließen Maurikios keine andere Wahl, als mit den römischen Truppen in den Konflikt einzugreifen; bewaffnete Auseinandersetzungen mit dem Erzfeind bargen allerdings das Risiko, die

103 Zu Johannes’ Aktivitäten in Ägypten siehe Van Ginkel 2002, 232-234; Kaegi 2003, 80 f. und Rapp 2004. Zu der hagiographischen Tradition zu Johannes dem Almosengeber siehe oben S. 19. Rapp arbeitet heraus, dass Niketas und Johannes durch die rituellen Verwandtschaftsbeziehungen der adelphopoiesis und synteknia miteinander verbunden waren (siehe ebd., bes. 124 f.; vgl. Kaegi 2003, 59). Sie betont außerdem die Erklärungsnot der Hagiographen, Johannes als eher untypischem Heiligem Mann im Rahmen des Genres gerecht zu werden (ebd. 123f.). Erst als die Perser auch Ägypten besetzt hatten, kehrte Johannes nach Zypern zurück, wo er kurz darauf verstarb.

104 Geburt Epiphanias: Chron. Pasch. AD 611; Theoph. Conf AM 6102 (299); Geburt Herakleios Konstantin: Chron. Pasch. AD 612; Theoph. Conf AM 6103 (300); zum Tod der Eudokia siehe ebd. und Nik. Brev. 3 zur Beerdigung in der Apostelkirche; zu der Krönung der Epiphania siehe Chron. Pasch. AD 612; Theoph. Conf AM 6104 (300).

105 Zur Krönung des Herakleios Konstantin siehe Chron. Pasch. AD 613; Theoph. Conf AM 6104 (300) gibt als Termin den 25. Dezember 612 an; es gibt allerdings keinen Grund, das Zeugnis des Chron. Pasch. anzuzweifeln, da die Regierungsjahre des Herakleios Konstantin ab dem 22. Januar und nicht ab Dezember gerechnet wurden; siehe Whitby/Whitby 1989, 156 Anm. 436; vgl. Olster 1982, 399.

106 PLRE I, Flavius Arcadius 5 (99); PLRE I, Honorius 3; Leppin 2003, 127-133 zur Sicherung der Dynastie unter Theodosios I.; zu Theodosios’ Nachfolgeregelung auch Börm 2015a, 258; zur Krönung des Theodosios II. siehe Chron. Pasch. AD 402; zu Theodosios, Sohn des Maurikios, siehe oben S. $72 \mathrm{f}$.

107 Zur Bedeutung von Dynastie bei der Nachfolgeregelung siehe und Börm 2015a. 
politische Hierarchie der Hauptstadt zu destabilisieren. Bevor Maurikios weitere Schritte unternahm, krönte er seinen Sohn. ${ }^{108}$ Theodosios I. erhob seinen jüngeren Sohn Honorios im Alter von neun Jahren zum Augustus, als die Situation im Westen des Reiches ihm zu entgleiten drohte: Nach dem unerwarteten Tod des jungen Valentinian II. im Jahr 392 hatte der Heermeister Arbogast eigenmächtig Eugenius als Kaiser proklamiert. Bevor Theodosios gegen den Usurpator ins Feld zog, krönte er nach Arkadios demonstrativ auch seinen zweiten Sohn Honorios, der nach Theodosios’ Tod 395 tatsächlich die Herrschaft im Westen des Reiches übernahm. ${ }^{109}$ Erklärungsbedürftig ist demnach nicht der Umstand, dass ein Kaiser seinen leiblichen Sohn zum Augustus erhob, sondern vielmehr der genaue Zeitpunkt, zu dem dieser Akt erfolgte. ${ }^{110}$

Die frühe Krönung von Epiphania und Herakleios Konstantin ist vor dem Hintergrund der prekären Situation zu verstehen, in der sich Herakleios zu Beginn seiner Regierung befand. In diesem Zusammenhang konnte die Designation seines Sohnes zum Nachfolger für Herakleios eine Reihe positiver Konsequenzen zeitigen: die Stärkung des Verhältnisses zu den hauptstädtischen Akzeptanzgruppen, die Etablierung einer klar umrissenen Dynastie (in Abgrenzung zu möglichen Konkurrenten) und die Benennung nicht nur eines Nachfolgers, sondern gleichzeitig eines Stellvertreters.

Die Krönungen gaben Herakleios die Möglichkeit, mit den verschiedenen Gruppen der Hauptstadt in Interaktion zu treten, was besonders bei der Erhebung des Herakleios Konstantin deutlich wird. Wie bereits im vorigen Kapitel gezeigt, adressierte das Krönungsritual sukzessive verschiedene Öffentlichkeiten. Konträr zum Ablauf von Herakleios' eigener Krönung begannen die Feierlichkeiten für seinen Sohn im Palast, genauer gesagt der Stephanskirche, wo sich die säkulare und klerikale Elite der Hauptstadt versammelt hatte. Nachdem Herakleios dort die eigentliche Krönung vollzogen hatte - die Rolle des Koronators fiel nun wieder dem Vater anstelle des Patriarchen $\mathrm{zu}$-, wurde der junge Augustus ins Kathisma des Hippodrom gebracht, von Demen und Senatoren akklamiert und schließlich in die Hagia Sophia geführt, wo ein weiterer Gottesdienst in Anwesenheit der Gemeinde stattfand. ${ }^{111}$ Indem Herakleios seinen Sohn krönte und den Eliten ebenso wie der Bevölkerung Konstantinopels präsentierte, konnte er den Moment des performativen Consensus universorum, der seine eigene Herrschaft eingeleitet und ihn im Oktober 610 zum Kaiser gemacht hatte, wiederholen und sich der Akzeptanz der hauptstädtischen Gruppen versichern.

Dass Kaiser, die mit ihrem Vorgänger nicht verwandtschaftlich verbunden waren, sich in besonderem Maße darum bemühten, eine eigene Dynastie zu etablieren, ist per

108 Dazu siehe oben S. $72 \mathrm{f}$.

109 Siehe Leppin 2003, 208 zur Krönung des Honorius und ders. 2003, 205-216 zur Usurpation des Eugenios; außerdem Szidat 1979.

110 Eine klare Vorstellung davon, in bzw. ab welchem Alter Söhne der Kaiser bereit waren, neben ihren Vätern in den Rang des Augustus einzutreten, bestand nicht. Es lag in der Entscheidung des Senior Augustus, den Zeitpunkt festzulegen.

111 Der Ablauf der Krönung wird in Chron. Pasch. AD 613 geschildert. 
se nicht verwunderlich. ${ }^{112}$ Im Falle des Herakleios bestand aufgrund eines konkreten Störfaktors allerdings noch höhere Dringlichkeit. Bereits Phokas hatte sich mit dem Problem konfrontiert gesehen, dass nach dem Machtwechsel von 602 Gerüchte vom Überleben des Augustus Theodosios, Maurikios' ältestem Sohn, kursierten, die als politisches Argument gegen ihn instrumentalisiert werden konnten. Derartige Gerüchte waren offenbar auch beinahe zehn Jahre später noch nicht ganz ausgemerzt; laut der Armenischen Geschichte des Sebeos wies der Perserkönig Chosroes II. Herakleios' Delegation mit dem Verweis darauf zurück, dass er den Theodosios als Kaiser der Römer betrachte. ${ }^{113}$ Herakleios befand sich in einem Dilemma: Einerseits versuchte er, Phokas' Sturz und seinen Griff nach der Macht als Rache für das Massaker an Maurikios darzustellen; ${ }^{114}$ andererseits hielt sich mit dem angeblichen Theodosios ein ernstzunehmender Konkurrent. Allein das hartnäckige Gerücht von dessen Überleben konnte das neue Regime in Konstantinopel destabilisieren. Herakleios begegnete diesem Dilemma, indem er den Fokus auf die eigene Familie lenkte und die Erinnerung an Maurikios’ Erbe(n) durch die Etablierung einer eigenen, fest in der Hauptstadt verankerten Dynastie überschrieb. ${ }^{115}$ Mit der Krönung des Herakleios Konstantin - also der unmissverständlichen Benennung eines Nachfolgers - kam er darüber hinaus einflussreichen Akteuren zuvor, die danach trachten konnten, sich im Sinne des eigenen Machtzuwachses in die Nachfolgeregelung einzumischen.

Dass Herakleios seinen Sohn derart früh zum Augustus krönte, macht schließlich auch den Zusammenhang zwischen Familien- und Militärpolitik deutlich. Die Erhebung im Januar 613 erfolgte unmittelbar bevor Herakleios im Frühjahr 613 nach Syrien aufbrach, um das römische Heer im Kampf gegen die Perser anzuführen; Sebeos

112 Verwandtschaftliche Bindungen zum Vorgänger konnten auch ex post noch hergestellt werden: so geschehen bei Markian, der nach seiner Krönung die Schwester seines Vorgängers Theodosios II. heiratete, und bei Anastasios, der die Witwe des Zenon ehelichte. Die einzigen oströmischen Kaiser, die im 5. und 6. Jahrhundert nicht mit der Familie des Vorgängers verbunden waren, waren Leon I. und Justin I. Leon I. erhob seinen Enkel Leon II. zum Augustus und Justin I. seinen Neffen Justinian erst zum Caesar und schließlich zum Augustus.

113 Sebeos 34 (Thomson/Howard-Johnston I, 66); zu der Delegation des Herakleios an Chosroes siehe auch Theoph. Conf. AM 6105 (De Boor 300); Mich. Syr. 11.1 (Chabot II, 400); Chron. 1234, 91 (Chabot I, 177). Bis auf Theophanes Confessor berichtet keine griechische Quelle von einer derartigen Delegation und Theophanes' Information könnte durchaus aus der syrischen Tradition stammen; Mango/Scott 1997, 430 f. Anm. 1 zweifeln deshalb die Historizität der Delegation an. Der in Chron. Pasch. AD 615 erhaltene Brief des Senates an Chosroes gibt überdies an, Herakleios habe nach seiner Erhebung aufgrund der chaotischen politischen Lage keine Gelegenheit gefunden, sich mit einer Delegation dem Chosroes vorzustellen.

114 Dies äußert sich in Chron. Pasch. AD 615 und Nik. Brev. 2.

115 Theophylakt Simokattes, der sein Geschichtswerk nach dem Ende des Perserkrieges 628 vollendete und Herakleios wohlgesinnt war, war offensichtlich darum bemüht zu betonen, dass Theodosios ebenso wie sein Vater und seine Brüder im November 602 starb; siehe Hist. 8.13.3 - 6, 8.15.8f. Zu dieser Problematik ausführlich Booth 2019. 
macht den Kausalzusammenhang dieser beiden Ereignisse explizit. ${ }^{116}$ Als Herakleios die Hauptstadt entgegen gängiger Verhaltenserwartungen an den Monarchen erstmals für längere Zeit verließ, um an der Spitze der römischen Truppen gegen die Perser zu ziehen, hatte er nicht nur ein klares Statement hinsichtlich seiner Nachfolge gesetzt; mit Herakleios Konstantin befand sich außerdem weiterhin ein Augustus in Konstantinopel - ein Augustus, der trotz seines jungen Alter zumindest die Funktion als zeremonieller Mittelpunkt des hauptstädtischen Beziehungsgeflechtes ausfüllen konnte. Die Anwesenheit des Herakleios Konstantin garantierte, dass Konstantinopel trotz Herakleios' vorübergehender Abwesenheit auf ihn bzw. seine Familie bezogen blieb. Die stabilisierende Wirkung dieser Konstellation in Hinblick auf Herakleios' Herrschaft sollte sich indes erst über ein Jahrzehnt später vollends offenbaren.

\subsubsection{Münzprägung}

Die gemeinsame Herrschaft von Vater und Sohn wurde ab 613 nicht nur im offiziellen Datierungsformular angegeben, ${ }^{117}$ sondern fand ihren Ausdruck auch in der Münzprägung: Alle ab 613 ausgegebenen Nominale stellten nicht Herakleios allein, sondern das kaiserliche Kollegium, seine Familie bzw. die von ihm zu begründende Dynastie in den Vordergrund. Im Gegensatz zu der Münzprägung früherer Jahrhunderte, die sich durch eine Vielzahl von Typen - die spezifische Kombination von Bild- und Textelementen - ausgezeichnet und teilweise sehr differenziert auf aktuelle Ereignisse reagiert hatte, ist in der Spätantike eine fortschreitende Schematisierung von Bildprogramm und Beischriften nachzuvollziehen. ${ }^{118}$ Dieser Entwicklung entspricht auch die herakleische Münzprägung; doch gerade die Beobachtung von deren genereller Uniformität einerseits und den wenigen Modifikationen des Prägeprogramms andererseits ermöglichen wichtige Rückschlüsse darauf, wie Herakleios seine Herrschaft konzipierte und repräsentierte.

Ein Überblick über die herakleischen Münzen offenbart folgende Charakteristika: ${ }^{119}$ Prägungen der Jahre 608-610 aus Karthago, Alexandria und Zypern, die Herakleios und seinen Vater durch Tracht und Beischrift als Konsuln auszeichnen, fanden nach der Krönung keinen Widerhall mehr; ihr bereits betonter Ausnahme-

116 Sebeos 34 (Thomson/Howard-Johnston I, 57f.): „At that time Heraclius made his son Constantine king; he put him in the charge of the senate, entrusted him to all the magnates of the palace, and confirmed him on the throne of his kingdom. He himself, having adopted the title of general, with his brother T‘ēodos gathered the multitude of his troops and set out for Asorestan, to the region of Antioch."

117 Chron. Pasch. AD 613.

118 Siehe Maier 2019, 81-85 mit weiterer Literatur zur Analyse spätantiker Münzprägungen.

$119 \mathrm{Zu}$ den herakleischen Münzen siehe DOC II.1, 216-221, Taf. 8-22; außerdem detailliert zu den verschiedenen Prägestätten und Nominalen MIB III, 83-122, Taf. 1-19. 
charakter wird damit nochmals verdeutlicht. ${ }^{120}$ Die Averse der Solidi, die ab Oktober 610 in Konstantinopel geprägt wurden, ${ }^{121}$ ziert stattdessen die frontale Büste des Herakleios in militärischer Tracht, mit Rüstung und Paludamentum. Auf dem bärtigen Kopf trägt er eine Krone mit seitlichen Pendilien, einem frontal über einer Scheibe aufragenden Kreuz und rückwärtigem Federschmuck, in der rechten Hand ein Kreuz. Als Beischrift finden sich leicht variierende Akronyme von DOMINUS NOSTER HERACLIUS PERPETUUS AUGUSTUS. Auf den Reversen prangt das bereits bekannte Stufenkreuz mit der Beischrift VICTORIA AUG(USTI). Diese Darstellung orientiert sich weitestgehend an den über Jahrhunderte etablierten Konventionen römischer-imperialer Münzprägung, die das Brustbild des Kaisers der Regel nach - mit selteneren Ausnahmen $^{122}$ - in militärischer Tracht präsentierte und ab dem 4. Jahrhundert sukzessive durch christliche Symbolik ergänzte. ${ }^{123}$ Wie bereits bei seinem Vorgänger Phokas fand allerdings auch bei Herakleios ein individualisierter Portraittyp Anwendung, dessen Züge sich vor allem in einer über die Jahre changierenden Barttracht äußern. ${ }^{124}$

Während das Revers-Bild auch nach 613 praktisch unverändert blieb, erschien auf dem Avers der Solidi neben dem Portrait des Herakleios nun auch das seines Sohnes Herakleios Konstantin, umgeben von der Beischrift D(OMINI) N(OSTRI) HERACLIUS ET HERA(CLIUS) CONST(ANTINUS) P(ER)P(ETUI) AUGUSTI. Der Junior Augustus befindet sich kleiner als der Senior und ohne Bart auf der vom Betrachter aus rechten, also hierarchisch untergeordneten Seite. ${ }^{125}$ Nach der Krönung seines Sohnes 613 wurde Herakleios auf keinem Nominal mehr allein abgebildet, sondern immer in Begleitung des Herakleios Konstantin: Auf den Aversen der Kupfermünzen erscheinen die beiden Kaiser in der Regel stehend anstatt im Brustbild; ${ }^{126}$ auf den Silber-Hexagrammen, die 615 eingeführt wurden, in thronender Position. ${ }^{127} \mathrm{Ab} 632$ stieß dann mit Heraklonas, Herakleios' Sohn aus seiner zweiten Ehe mit Martina, ein dritter Protagonist auf dem Avers der Solidi hinzu: Die zwei Büsten bzw. thronenden Figuren

$120 \mathrm{Zu}$ den Konsulatsprägungen siehe oben S. 95-97.

121 Solange keine bemerkenswerten Abweichungen $\mathrm{zu}$ verzeichnen sind, werde ich mich im Folgenden auf die Prägungen aus Konstantinopel konzentrieren; zu anderen Prägestätten siehe DOC II.1, $230-241$.

122 Ausnahmen sind etwa Prägungen, die den Antritt eines kaiserlichen Konsulates anzeigen und den Kaiser entsprechend in der Tracht der Konsuln darstellen, Beispiele verschiedener Kaiser des 6. Jahrhundert in DOC I, 378 (Index s.v. „Consular robes and insignia”); außerdem Doppelportraits, die ich im Folgenden noch eingehender besprechen werde.

123 Zur Entwicklung der Münzprägung im 7. Jahrhundert siehe DOC II.1, 65-68; außerdem Olster 1982, 399.

124 Zu den Portraits siehe DOC II.1, 88-94; zu Phokas’ Münzen siehe oben S. 145.

125 Zum neuen Münztyp siehe DOC II.1, 221-223, 247-249; zur Datierung außerdem Grierson 1959 und Bellinger 1966. Eine Übersicht über die verschiedenen Nominale findet sich auch in MIB III, 83122 mit Taf. 1-19.

126 Kupfer-Prägungen: DOC II.1, 225-229, 274-307.

127 Silber-Hexagramme: DOC II.1, 270-274; zur Einführung des Silber-Hexagramms 615 siehe Yannopoulos 1978 und DOC II.1, 17-18, 115-117. 
weichen damit drei frontal stehenden Figuren. ${ }^{128}$ Mit dem Wechsel vom Einzel- zum Doppelportrait im Jahr 613 wandelte sich auch die Tracht des bzw. der Abgebildeten: Anstatt Rüstung und Paludamentum tragen die beiden Augusti Chlamys (den beinahe bodenlangen Purpurmantel) und eine mit Kreuz versehene Krone - die militärische Tracht wich also der zivilen. ${ }^{129}$ Das zivile Gewand etablierte sich als ein kontinuierliches Merkmal auf allen Nominalen der herakleischen Münzprägung, durchbrochen allein von einem kurzzeitig ausgegebenen Bronze-Typ der Jahre 629-631. ${ }^{130}$ Es lässt sich also eine auf den ersten Blick paradoxe Entwicklung konstatieren: Während die sesshaften Kaiser des 5. und 6. Jahrhunderts auf den Münzen an militärischer Repräsentation festhielten, brachen ausgerechnet Prägungen des Herakleios, der erstmals wieder persönlich Truppen ins Feld führte, mit dieser Tradition.

Dieses Paradox löst sich jedoch, wenn man die herakleischen Münzen im Kontext spätrömischer Präge- und Darstellungskonventionen bewertet. Doppelportraits zweier Augusti auf Münzen sind keine grundsätzliche Neuerung. Sie dienten bereits in den vorangehenden Jahrhunderten als Instrument, um Herrschaftskonstellationen, Familienverhältnisse und Nachfolgeregelungen zu indizieren; sowohl Kaiserkollegen als auch Eheleute wurden in Doppelportraits dargestellt. Im 4. Jahrhundert finden sich Mehrfachportraits regelmäßig auf Goldprägungen: Während der Avers dem bzw. im Falle einer Samtherrschaft - einem der Augusti vorbehalten war, konnte auf den Reversen die spezifische Herrschaftskonstellation zum Ausdruck gebracht werden; Konstantin zeigte sich in der Mitte seiner Söhne, die Augusti Theodosios und Valentinian I. erschienen in Eintracht. ${ }^{131}$ Ähnlich verhielt es sich auch im 5. Jahrhundert: Während ihres jeweiligen Kondominats wurden Leo I. und Leo II. (473/4), Leo II. und Zeno (474) sowie Basiliskos und Markos (475/6) auf den Reversen der Solidi nebeneinander in thronender Position und zivilem Gewand dargestellt; die Averse trugen weiterhin das typische Kaiserportrait des Senior Augustus in militärischer Tracht. ${ }^{132}$ Ab dem 6. Jahrhundert fanden Doppelportraits schließlich auch auf dem Avers An-

128 MIB III, 85. Heraklonas wurde 632 zum Caesar gekrönt, siehe Theoph. Conf. AM 6108 (De Boor 301), der das Ereignis allerdings einen Indiktions-Zyklus zu früh ansetzt, siehe Mango/Scott 1997, 433 Anm. 2. Vgl. Nik. Brev. 19, ohne absolute Datierung, allerdings mit der Angabe, dass dies nach der Rückkehr des Herakleios in die Hauptstad in Folge des Sieges über die Perser erfolgte. 638 wurde Heraklonas dann zum Augustus befördert, siehe De cerim. 2.27; Nik. Brev. 25. Der Statuswechsel des Heraklonas vom Caesar zum Augusuts 638 wird auf den Solidi durch eine Modifikation der Kopfbedeckung angezeigt, siehe DOC II.1, 223-225. Auf den Silber-Hexagrammen und Kupfer-Nominalen wurde Heraklonas erst nach seiner Krönung zum Augustus 638 einbezogen; siehe DOC II.1, 225-229. 129 Olster 1982, 399.

130 Vgl. DOC II.1, 76-78 zum Kaiser im zivilen Gewand; zu der Ausnahme siehe ebd., 74, 226-228 (Follis Class 5) und unten S. 235f.

131 Siehe MacCormack 1981, 202f. mit Taf. 44-50. Vgl. ein Solidus-Exagion aus Bronze, das auf dem Avers Theodosios I. mit seinen beiden Söhnen Arkadios und Honorios darstellt, siehe Kalavrezou 2003, 51, Abb. 9a f.

132 Leon I. \& Leon II.: RIC X, Taf. 24 Nr. 636-638; Leon II. \& Zenon: RIC X, Taf. 27 Nr. 803 f.; Basiliskos und Markus: RIC X, Taf. 29 Nr. 1019, $1022 \mathrm{f}$. 
wendung. Nach seiner Erhebung zum Augustus am 4. April 527 erschien Justinian neben seinem Onkel auf den Aversen der Solidi, ebenfalls thronend und mit Chlamys. ${ }^{133}$ Auch Justin II. und Tiberios erschienen im Doppelportrait; allerdings zierten in diesem Fall Büsten anstatt thronender Figuren die Averse der Solidi. ${ }^{134}$ Ab Justin II. etablierte sich außerdem die Praxis, die zur Augusta erhobene Ehefrau des regierenden Kaisers neben diesem stehend auf dem Avers abzubilden - so geschehen bei Justin II. und Sophia, Tiberios und Anastasia, Maurikios und Konstantina sowie Phokas und Leontia. ${ }^{135}$ Diese Form der stehenden Doppelportraits eines Ehepaares findet sich allerdings nicht auf den Solidi, sondern allein auf den weniger wertigen Kupfer-Nominalen.

Die herakleische Münzprägung eignete sich ab 613 bestehende Typen des Doppelportraits an und übertrug diese konsequent auf die Averse aller Nominale: Büsten auf den Solidi, stehende Figuren auf den Kupfer-Münzen sowie thronende auf den ab 615 ausgegebenen Silber-Hexagrammen. ${ }^{136}$ Die Entscheidung zugunsten der zivilen Chlamys als typischer Tracht der Doppelportraits griff dabei auf etablierte Konventionen zurück. In den Chlamys-tragenden Doppel- bzw. Dreierportraits auf allen herakleischen Münz-Nominalen offenbart sich die Kombination symbolischer Darstellungsformen, welche traditionell einerseits mit Kondominat, andererseits mit Familienbeziehungen verbunden waren. ${ }^{137}$ Bei der Beobachtung dieser Traditionsbezogenheit darf allerdings die Eigenheit der herakleischen Prägungen nicht aus dem Blick verloren werden. Dass die Konsequenz, mit der Herakleios’ Münzen den Fokus auf die kaiserliche Familie richteten, wahrlich außergewöhnlich war, offenbart sich besonders im Vergleich zu den Prägungen seines Vorgängers Maurikios. Maurikios, der als erster Kaiser nach Arkadios wieder einen leiblichen Sohn hatte, krönte diesen zwar 590 zum Augustus, ließ die Erhebung jedoch nicht auf Münzen vermerken zumindest nicht konsequent: Theodosios als designierter Nachfolger findet sich nur auf Kupfermünzen der Chersones; während der Avers weiter Maurikios und Konstantina vorbehalten ist, erscheint der Junior Augustus nur auf dem Revers. ${ }^{138}$

Über die ikonographische Kontextualisierung der herakleischen Münzen hinaus stellt sich die Frage, welche Wirkung die Prägungen im Rahmen politischer Kommunikation und kaiserlicher Repräsentation entfalteten. Lässt sich in dem spezifi-

133 DOC I, 57-61 mit Taf. 12.

134 MIB II, 51 mit Taf. 10; DOC I, 263; Grierson 1955, 64f.; Olster 1982, 400.

135 Olster 1982, 399f. Zu Justin II. und Sophia siehe MIB II, 44-49 mit Taf. 4-8. Doppelportraits von Maurikios und Konstantina sind, soweit ich sehe, nur auf Kupfermünzen aus Thessaloniki und der Chersones bezeugt; siehe MIB II, 68 - 75 mit Taf. 26, 28; zu Phokas und Leontia siehe MIB II, 80 - 83 mit Taf. $32-35$.

136 Eine Übersicht über die verschiedenen Nominale findet sich in MIB III, 83-122 mit Taf. 1-19 und DOC II.1, 216-383 mit Taf. 8-22.

137 Siehe Olster 1982, 401.

138 Siehe Olster 1982, 400 f.; MIB II, 74 f. mit Taf. 28. Dass Theodosios kaum auf Münzen Beachtung findet, passt zu der Notiz im Chron. Pasch. AD 590, dass er zwar von Maurikios gekrönt, aber nicht von der Öffentlichkeit akklamiert oder in die offiziellen Register aufgenommen wurde. 
schen Bild- und Textprogramm tatsächlich die gezielte Öffentlichkeitsarbeit des Herakleios erkennen? ${ }^{139}$ Im Laufe des Prinzipats wurde die Münzprägung sukzessive in die kaiserliche Administration eingegliedert; die über das Reich verteilten Prägestätten operierten in der Regel nicht individuell, sondern wurden zentral gesteuert. Die Entwicklung von Bild- und Textprogramm der Münzen geschah demnach zumindest herrschernah bzw. konnte vom regierenden Kaiser gezielt beeinflusst werden. Frisch geprägte Münzen fanden in verschiedenen Kontexten Anwendung: Den größten Ausgabeposten stellte die Finanzierung des römischen Heeres dar; Münzen wurden an Soldaten aller Dienstgrade ausgezahlt, sie fanden ihren Weg in die Verwaltung, den kaiserlichen Hof, finanzierten kaiserliche Bautätigkeit, wurden im Zuge von öffentlichen Geldspenden in Umlauf gebracht, zirkulierten von dort aus weiter und drangen bis in die entlegensten Winkel des Reiches (und sogar darüber hinaus) vor. ${ }^{140}$ Trotz fortschreitender Erkenntnisse hinsichtlich antiker Münzproduktion und -Zirkulation wird die Frage nach der kommunikativen Wirkung des Prägeprogramms weiterhin kontrovers diskutiert; der Auffassung von Münzen als ,Propagandamedium‘ kaiserlicher Repräsentation, gar als Nachrichtenmedium, steht die These gegenüber, dass die retrospektive Analyse einzelner Typen dazu verleite, deren differenzierte Wahrnehmung durch die zeitgenössischen Rezipienten zu überschätzen. ${ }^{141}$ Joachim Szidat schließt sich in einem Aufsatz zu Münzen des Kaisers Julian zwar insgesamt eher dem Lager der Skeptiker an; allerdings gesteht er ein, dass Prägeprogramme durchaus Themen aufgreifen und betonen konnten, die - aufgrund ihrer Präsenz in anderen Medien - potentiellen Rezipienten bereits als Teil eines breiteren öffentlichen Diskurses vertraut waren. ${ }^{142}$ Diese vorsichtige Einschätzung lässt sich auch auf die herakleische Münzprägung anwenden. ${ }^{143}$ Die Quellen geben eine Reihe von Hinweisen darauf, dass Herakleios nicht nur die Erhebung seines Sohnes zum Augustus öffentlich zelebrierte, sondern die Präsenz eines Kollegen und designierten Nachfolgers über das Ereignis der Krönung hinaus regelmäßig betonte und damit das Kondominat in der öffentlichen Wahrnehmung zu verstetigen suchte. ${ }^{144}$ Dass Herakleios

139 Methodische Fragen im Zusammenhang mit der Aus- und Bewertung von Münzen adressiert ausführliche Wienand 2012, 43-86; außerdem Maier 2019, 81-85.

140 Wienand 2012, 43f. Zu Prägestätten im 7. Jahrhundert siehe DOC II.1, 33-53 und MIB III, 14-20. 141 Diese Debatte vollzieht Wienand 2012, 45 f. nach; außerdem Maier 2019, 82f., beide mit weiterer Literatur. Die Skeptiker berufen sich in der Regel auf Jones 1956.

142 Szidat 1981, $30 \mathrm{f}$.

143 Dass eine angemessene Wertung von Münzprägung, von deren kommunikativer Funktion und Wirkung, ein tiefes Verständnis des numismatischen Metiers voraussetzt, hat Wienand 2012 eindrucksvoll gezeigt; eine derartige Tiefenuntersuchung kann ich an dieser Stelle nicht leisten.

144 Dies wird vor allem in den Situationen deutlich, als Herakleios die Hauptstadt verließ und seinen Sohn dezidiert als Stellvertreter installierte, siehe Sebeos 34 (Thomson/Howard-Johnston I, 68). Auf die Nennung des Herakleios Konstantin im reichsweit geltenden Datierungsformular habe ich bereits hingewiesen; siehe Chron. Pasch. AD 613. Obwohl es dafür in den Quellen keinen expliziten Hinweis gibt, gehe ich davon aus, dass das Bild des Herakleios Konstantin nach seiner Krönung, entsprechend 
Konstantin - im Gegensatz zu Theodosios einige Jahrzehnte zuvor - derart früh und konsequent auf allen Nominalen als Augustus neben seinem Vater erschien, entspricht dieser Praxis; die These, dass das Prägeprogramm als Teil einer gezielten Öffentlichkeitspolitik des Kaisers zu werten ist, wird dadurch untermauert.

Zuletzt hat Johannes Wienand in Bezug auf die Münzprägung Konstantins gezeigt, dass eine Berücksichtigung der Distributionskontexte für das Verständnis des kommunikativen Gehaltes von Münzen unerlässlich ist. Verschiedene Nominale wurden an unterschiedliche Gruppen ausgehändigt bzw. erreichten diese durch Münzumlauf: Während Solidi bzw. Gold-multipla in der Regel hohen Funktionsträgern vorbehalten waren, drangen Kupferprägungen $\mathrm{zu}$ wesentlich breiteren Kreisen von Zivilbevölkerung und Heer vor. Anhand von Bild-Text-Kombinationen, die zwischen Nominalen differenzierten, konnte der Kaiser - so Wienand in Bezug auf Konstantin - die Bedürfnisse und Erwartungen unterschiedlicher Gruppen gezielt adressieren. ${ }^{145} \mathrm{Im}$ Vergleich zu den konstantinischen Prägungen zeichnen sich die verschiedenen Nominale unter Herakleios durch einen recht hohen Grad an Homogenität aus. Die Avers/Revers-Gestaltungen weichen zwar im Detail, wie oben gezeigt, durchaus voneinander ab (Büsten, thronende/stehende Figuren); der semantische Gehalt des Prägeprogramms wird dadurch jedoch nur in Ausnahmen signifikant beeinträchtigt. ${ }^{146}$ Die Betonung der kaiserlichen Familie zieht sich ab dem Jahr 613 derart stringent über alle Typen und Nominale, dass zumindest in diesem Zusammenhang der Aspekt der Distributionskontexte vernachlässigt werden kann. Im Münzprogramm offenbart sich Herakleios’ Ambition, seine Familie im Sinne einer zu gründenden Dynastie an der Spitze des Gemeinwesens zu verankern und diesen zentralen Aspekt seiner Herrschaft gegenüber einem möglichst breiten Querschnitt der Gesellschaft zu kommunizieren. ${ }^{147}$

etablierter Praxis, in die Provinzen geschickt wurde und dort sowohl beim Heer als auch in den Städten neben dem des Vaters präsent war.

$145 \mathrm{Zu}$ dem Begriff ,Distributionskontext` siehe Wienand 2012, 47; außerdem detailliert ebd. 66-86. 146 Signifikante Abweichungen sind folgende: Die ab 615 eingeführten Silber-Hexagramme tragen auf dem Revers die Beischrift DEUS ADIUTA ROMANIS als Reaktion (so die Vermutung) auf die sich weiter zuspitzende außenpolitische Krise; zu den Silber-Hexagrammen siehe DOC II.1, 17f., 115-117, 270 - 274, Taf. 10. Ab 615/6 erschien auf den Aversen der Kupfer-Nominale neben den beiden Augusti eine weibliche Person, dazu siehe im Folgenden. Wie bereits erwähnt wurden Herakleios und Herakleios Konstantin zwischen 629 und 631 auf den Folles in militärischer Tracht und nicht wie sonst in Zivil dargestellt; dazu siehe S. $235 \mathrm{f}$.

$147 \mathrm{Ob}$ und wie die herakleische Münzprägung wahrgenommen wurde, ist eine andere Frage. Eine mögliche Antwort liefert Johannes von Nikiu (116.3) in Bezug auf Ägypten. Die Passage verdeutlicht allerdings auch, dass die Wahrnehmung eklatant vom ursprünglichen Aussageziel abweichen konnte: "And some said: 'The death of Heraclius is due to his stamping the gold coinage with the figures of the three emperors - that is, his own and of his two sons on the right hand and on the left - and so no room was found for inscribing the name of the Roman empire.' And after the death of Heraclius they obliterated those three figures." Übers. nach Charles 1916. 


\subsubsection{Endogamie}

Der letzte Aspekt in Zusammenhang mit Herakleios' Familienpolitik ist gleichzeitig der in der Forschung umstrittenste. Nach dem frühen Tod seiner ersten Frau Eudokia heiratete Herakleios seine Nichte Martina, die Tochter seiner Schwester - eine Ehe, mit der er gegen römisches Recht verstieß. ${ }^{148}$ Die inzestuöse, im christlichen Sinne als sündhaft wahrgenommene Verbindung sorgte bereits bei Herakleios' Zeitgenossen für Irritation, ${ }^{149}$ prägte die Erinnerung an den Kaiser im negativen Sinne ${ }^{150}$ und stieß zuletzt bei Historiker/innen auf Unverständnis. Nikephoros verurteilt Herakleios für

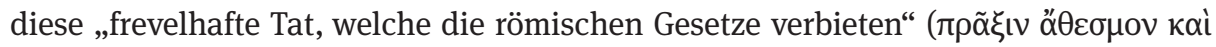

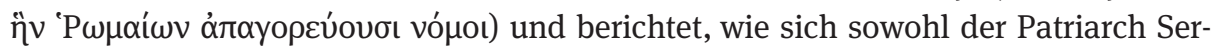
gios als auch die Zirkusparteien im Hippodrom gegen die Verbindung ausgesprochen hätten; Herakleios indes habe an seiner Entscheidung festgehalten und die Ehe schließen lassen. ${ }^{151}$ Warum setzte sich Herakleios mit einer derartigen Entscheidung über geltendes Recht und Moralvorstellungen hinweg? Die Forschung konnte auf diese Frage noch keine befriedigende Antwort formulieren; ${ }^{152}$ Erklärungsmodelle, die das Gefühlsleben des Kaisers in den Vordergrund stellen, sind methodisch kaum valide. ${ }^{153}$ Die hier gewählte Herangehensweise indes legt nahe, dass sich in Herakleios' Hochzeit mit der eigenen Nichte eine endogame Familienpolitik äußert, die - analog zu den bereits geschilderten Maßnahmen - auf die Stärkung der Herrschaftsverhältnisse und Abwehr potentieller Konkurrenten abzielte.

Bereits die Datierung von Herakleios' zweiter Hochzeit bereitet Probleme. Allein Theophanes Confessor gibt eine absolute Chronologie, welche die Eheschließung

148 Gemäß Cod. Theod. 3.12.1 (Gesetz aus dem Jahr 342) waren Ehen zwischen Onkel und Nichte untersagt; siehe dazu Kaegi 2003, $106 \mathrm{f}$; zu Martina siehe Garland 1999, 63-72.

149 Entgegen der Annahme von Speck 1988, 268- 270 und ders. 1997, 463 Anm. 54, dass die Kritik an der Ehe prinzipiell nur a posteriori ausgesprochen worden sei, zeugt Ant. Strateg. (Conybeare 516) davon, dass die Ehe bereits von Zeitgenossen als sündhaft empfunden wurde.

150 Nik. Brev. 11, 20; Chron. 1234, 98 (Chabot I, 182f.); Mich Syr. 11.3a (Chabot II, 410).

151 Nik. Brev. 11; dazu Speck 1988, 267-271 und Mango 1990, 179f. Zu der Reaktion der Zirkusparteien vgl. Al. Cameron 1976, 339f., der die Stelle anders als Mango liest: Die Grünen hätten die Hochzeit unterstützt, nur die Blauen seien dagegen gewesen. Nikephoros berichtet außerdem von zwei Söhnen des Paares, Flavios und Theodosios, die beide behindert gewesen seien, was der Autor wiederum als gerechte Strafe für die unrechtmäßige Verbindung versteht. Zu diesen beiden Söhnen siehe Mango 1990, 179f. Dabei ist zu bedenken, dass manche Passagen des Breviariums - bzw. die von Nikephoros genutzten Quellen - Herakleios dezidiert kritisch gegenüberstehen. Die Frage, ob sein Bericht von den Ausschreitungen im Zusammenhang mit der Hochzeit authentisch ist, ob es also wirklich zu derartigen Szenen kam oder ob es sich dabei eher um eine retrospektive Verurteilung handelt, sollte zumindest bedacht werden.

152 Kaegi 2003, 107 stellt fest: „Heraclius tried to create new stability and resolve his dynastic problems by marrying Martina.” Allerdings erörtert er nicht, inwiefern die Ehe ein stabilisierende Wirkung hätte haben können.

153 So verfahren etwa Frolow 1953, 103 und Speck 1988, 33- 43. 
bereits kurz nach Eudokias Tod, ins Jahr 613/14, ansetzt. ${ }^{154}$ Der Chronograph fügt außerdem hinzu, Martina sei anlässlich der Hochzeit zur Augusta erhoben und im Augustaion, dem Empfangssaal im kaiserlichen Palast, durch den Patriarchen Sergios gekrönt worden. Nikephoros hingegen legt mit seiner relativen Chronologie nahe, dass die Hochzeit erst circa ein Jahrzehnt später, kurz vor Beginn der großen Gegenoffensive gegen die Perser, stattfand. ${ }^{155}$ Diese Diskrepanz ist schwer aufzulösen, zumal sowohl Theophanes als auch Nikephoros bisweilen schwerwiegende chronologische Ungenauigkeiten aufweisen. ${ }^{156}$ Zeitgenössische Quellen erwähnen die Hochzeit nicht; die Osterchronik vermerkt lediglich, dass Martina ihren Ehemann begleitete, als dieser im Frühjahr 624 gen Osten aufbrach. ${ }^{157}$ Sicher ist zunächst also nur dieser Terminus ante quem.

Ein weiterer Faktor, der bei der Datierungsfrage in Betracht gezogen werden kann, ist eine Modifikation der Kupfermünzen: Nachdem ab 613 das stehende Doppelportrait von Herakleios und Herakleios Konstantin die Averse geziert hatte, wurde ab 615/ 16 ein neuer Typ mit drei stehenden Figuren ausgegeben, datierbar durch die Beischrift des Regierungsjahres auf dem Revers. ${ }^{158}$ Die vom Betrachter aus links abge-

154 Theoph. Conf. AM 6105 (De Boor 300).

155 Nik. Brev. 11. Auch in der westsyrischen Tradition (Chron. 1234, 98f. [Chabot I, 182f.]; Mich Syr. 11.3a [Chabot II, 410]) wird die Verbindung erst in Zusammenhang mit Herakleios' Perserfeldzug erwähnt. Es ist allerdings nicht auszuschließen, dass die potentiell bereits länger geschlossene Ehe für die syrischen Chronisten erst im Zusammenhang mit der Präsenz von Herakleios und Martina im Osten erwähnenswert schien.

$156 \mathrm{Zu}$ chronologischen Ungenauigkeiten: Theoph. Conf. AM 6108 (De Boor 301), entsprechend 615/ 16, etwa vermerkt, dass Herakleios Konstantin den Konsulat antrat und seinen Halbbruder, „den anderen Konstantin“ (also Heraklonas), zum Caesar erhob. Dies geschah allerdings nachweislich erst im Jahr 632 (siehe Mango/Scott 1997, 433 Anm. 2). Theophanes scheint an dieser Stelle im Indiktionszyklus verrutscht zu sein - Indiktion 5 entspricht sowohl 615/16 als auch 631/32; siehe Speck 1988, 33-43 und Zuckerman 1995, 115. Befürworter einer späten Hochzeit argumentieren, dass Theophanes aufgrund seiner um 15 Jahre vorgezogenen Datierung der Erhebung des Heraklonas zwangsläufig auch die Hochzeit von dessen Eltern habe früher ansetzen müssen; siehe dazu unten. Ohne absolute Datierung berichtet Nikephoros erst von der Hochzeit (Brev. 11), dann von der Eroberung Jerusalems durch die Perser (Brev. 12) von 614 und direkt im Anschluss darauf von Herakleios' Aufbruch nach Osten über Pontos nach Lazica, der erwiesenermaßen 624 stattfand. Dies zeugt davon, dass Nikephoros die Ereigniszusammenhänge primär assoziativ und thematisch, nicht unbedingt chronologisch ordnete.

157 Chron. Pasch. AD 624. Der Umstand, dass selbst das Chron. Pasch., das dem Herakleios dezidiert positiv gegenübersteht und auf dem Höhepunkt des kaiserlichen Erfolges ca. 630 verfasst wurde, die Hochzeit nicht erwähnt, könnte mit der öffentlichen Missbilligung dieses Schrittes zusammenhängen. 158 Siehe die Tabelle in DOC II.1, 226; Zuckerman 1995, 114. Die Prägungen mit drei stehenden Figuren liefen bis 628/9, als diese wiederum durch Herakleios und Herakleios Konstantin in militärischer Tracht abgelöst wurden (DOC II.1, 226-228; der Wechsel wird deutlich von Taf. 6, 104 auf 105a.3). Prägungen provinzieller Münzstätten variieren leicht: Aus Karthago finden sich auch Silberprägungen, allerdings mit drei Büsten; ebenfalls drei Büsten auf den Bronzemünzen aus Rom und Ravenna; von der Chersones zwei stehende Figuren auf dem Avers und eine auf dem Revers - wie bereits bei den Münzen des Maurikios. 
bildete Figur zeichnet sich durch weibliches Gewand sowie eine aufwändigere Krone mit langen Pendilien aus; wie ihr männliches Pendant auf der rechten Seite trägt sie einen mit Kreuz besetzten Globus. ${ }^{159}$ Analog zu den sonstigen Prägungen ist die mittige Figur, die mit einem Stabkreuz in der Hand ihre Beisteher überragt, zweifelsohne als Herakleios zu lesen und die männliche Figur zu seiner Rechten als Herakleios Konstantin. Da die drei stehenden Figuren jedoch den Platz weitestgehend ausfüllen, wurde bei der Prägung auf eine benennende Beischrift verzichtet; somit stellt sich die Frage nach der Identität der weiblichen Figur. In Frage kommen entweder Herakleios' 612 zur Augusta gekrönte Tochter Epiphania oder seine zweite Ehefrau, die ebenfalls zur Augusta gekrönte Martina; in der Forschung finden sich Plädoyers für beide. Befürworter Martinas gehen entsprechend von einer Frühdatierung der Hochzeit gemäß Theophanes aus; ${ }^{160}$ Befürworter Epiphanias von einer Spätdatierung entlang Nikephoros' Bericht. ${ }^{161}$ Argumentiert man indes rein auf der Basis numismatischer Evidenz, so lässt sich festhalten, dass die Abbildung der Ehefrau des Kaisers auf den Aversen von Kupfermünzen seit Justin II. Tradition hatte. ${ }^{162}$ Die Tochter eines regierenden Kaisers war hingegen zuvor noch nie auf Münzen erschienen; es sollten noch zweihundert Jahre vergehen, bis byzantinische Prinzessinnen nachweislich in der Münzprägung berücksichtigt wurden. ${ }^{163}$

In Hinblick auf die herakleischen Münzen wurde herausgearbeitet, dass das Prägeprogramm sich zwar durch eine Reihe von Eigenheiten auszeichnete, dass sich die Gestaltung der Typen allerdings an etablierten Traditionen und Konventionen orientierte. Eine plötzliche und weitgehend unvermittelte Abbildung der Tochter des Kaisers entspricht kaum dem Charakter der herakleischen Prägungen - seine Ehefrau

159 Abbildungen siehe MIB III, Taf. 11 Nr. 161f., und DOC II.1, Taf. 12 Nr. 90a.1-96; zu Kronen der Kaiserinnen siehe ebd. 84 mit Abbildungen auf S. 82.

160 Für eine Frühdatierung Grierson in DOC II.1, 227 für 613/14; ebenso Olster 1982, 401; Whitby/ Whitby 1989, 167 Anm. 452; Garland 1999, 62. Geht man von einer Frühdatierung der Hochzeit aus, bleibt nur die Frage, warum Martina nicht direkt nach der Hochzeit (gemäß Theophanes 613/4), sondern erst 615/6 auf den Münzen erschien; dieselbe Frage ließe sich allerdings auch in Bezug auf Epiphania stellen, die ja bereits 612 zur Augusta erhoben worden war. Grierson in DOC II.1, 227 schlägt vor, dass die Aufnahme der Augusta in die Münzprägung mit der Geburt eines Sohnes zusammengehangen haben könnte (vgl. Theoph. Conf. AM 6101 [301]); zu den Söhnen von Herakleios und Martina siehe S. 174 Anm. 169.

161 Zuckerman 1995 argumentiert explizit für eine Spätdatierung; das Verschwinden der weiblichen Figur ab 628/629 bringt er damit in Zusammenhang, dass Epiphania 628 in Richtung Osten aufbrach, wo sie den Khagan der Türken ehelichen sollte. Dies erscheint mir jedoch wenig überzeugend - das Verschwinden der Epiphania/Martina könnte vielmehr darin begründet liegen, dass die beiden Augusti nach dem Sieg über die Perser in militärischer Tracht anstatt in ziviler dargestellt wurden und eine Frau in dieses Bildprogramm nicht gepasst hätte. Für eine späte Datierung der Hochzeit auch Mango 1990, 79f.; Speck 1997a und Kaegi 2003, 106. Speck 1988, 33-43, der auch von einer Spätdatierung ausgeht, verkompliziert die Situation unnötig, indem er annimmt, dass auf den Münzen erst Epiphania und ab 624 Martina abgebildet ist.

162 Dazu siehe oben S. 168.

163 Genauer gesagt Töchter des Kaisers Theophilos (829-842); siehe Zuckerman 1995, 120. 
mit einzubeziehen, wie es seine Vorgänger seit Justin II. getan hatten, hingegen schon. Die weibliche Figur als Martina zu identifizieren, ist auch vor dem Hintergrund der kommunikativen Funktion von Münzen plausibler: Als Rezipient der Prägungen war es die Bevölkerung gewöhnt, kaiserliche Ehefrauen auf den Aversen der Münzen zu sehen und die weibliche Figur auf Kupfernominalen auch als eben solche zu erkennen. ${ }^{164}$

Bevor ich zu einem abschließenden Urteil hinsichtlich der Datierung der Hochzeit komme, lohnt es sich, die anfangs geäußerte Frage, warum Herakleios eine derartige Verbindung einging, in die Überlegung mit einzubeziehen. Die Ehe zwischen Herakleios und Martina war nicht die einzige innerhalb der Familie, die zwischen nahen Verwandten geschlossen wurde: Anlässlich der Taufe seines Sohnes Herakleios Konstantin im Jahr 613 verlobte der Kaiser den Jungen mit Gregoria, der Tochter seines Cousins Niketas; die Ehe wurde im Jahr 630 geschlossen. ${ }^{165}$ Dieser Befund legt nahe, dass Herakleios ganz gezielt eine endogame Heiratspolitik verfolgte, wie sie auch in anderen vormodernen Monarchien gang und gäbe war, etwa bei den Ptolemäern eine endogame Heiratspolitik, die die verschiedenen Familienstränge noch enger miteinander verflocht: Herakleios entschied sich nicht, Martina zu heiraten; er entschied sich, seine Nichte zu heiraten. ${ }^{166}$ Mit der endogamen Heiratspolitik reagierte Herakleios auf die gängige Praxis hoher militärischer Funktionsträger, sich durch Heiratsallianzen mit der kaiserlichen Familie zu verbinden und dadurch Einfluss auf die Nachfolgeregelung zu nehmen. Dieses Phänomen, das als typisch für die politischen Prozesse des 5. und 6. Jahrhunderts identifiziert wurde, war zuletzt in der Person des Priskos erneut zu Tage getreten. ${ }^{167}$ Herakleios zeigte sich seinerseits darum bemüht, eine Dynastie zu begründen; er verfolgte dieses Ziel nicht nur, indem er seinen Sohn äußert früh zum Augustus erhob, sondern auch, indem er seine Familie konsequent von potentiellem Einfluss von außen abzuschotten suchte. ${ }^{168}$ Vor diesem Hintergrund halte ich es für plausibel, dass Herakleios nach dem Tod seiner ersten Frau 612 die familiäre Situation schnellstmöglich wieder zu konsolidieren suchte, anstatt über ein Jahrzehnt unverheiratet $\mathrm{zu}$ bleiben. Ich plädiere also dafür, die Hochzeit gemäß Theophanes’ Datierung ins Jahr 613/14 zu setzen - kurz nachdem Herakleios von der katastrophalen Syrien-Kampagne in die Hauptstadt zurückgekehrt war. ${ }^{169}$ Die weibliche Figur auf den Kupfer-Münzen identifiziere ich dementsprechend als Martina.

164 Auch der Umstand, dass die weibliche Figur nur auf den Kupfernominalen auftaucht, entspricht der ab Justin II. etablierten Praxis.

165 Nik. Brev. 5 (Verlobung); Nik. Brev. 17 (Eheschließung).

$166 \mathrm{Zu}$ Ehen zwischen Onkel und Nichte in der herodianischen Dynastie siehe Mitterauer 1991, $296 \mathrm{f}$. 167 Dazu siehe oben S. 153-156.

168 Vgl. Treadgold 1997, 289f.: „Presumably Heraclius hoped that blood relatives would be less likely than other connections to plot against his foundering government."

169 Herakleios und Martina hatten gemeinsam eine Reihe von Kindern: Theoph. Conf. AM 6106 (De Boor 301) vermerkt, Martina habe im Jahr nach der Hochzeit, also 615/16, einen Sohn zu Welt gebracht, 
Indem Herakleios seine Nichte heiratete, verstieß er gegen geltendes römisches Recht. ${ }^{170}$ In anderen Rechtstraditionen indes wurde die Ehe zwischen Onkel und Nichte nicht nur geduldet, sondern gar befürwortet: so etwa im mosaischen Recht des Alten Testamentes. ${ }^{171}$ In den Quellen gibt es keinerlei Hinweis darauf, dass Herakleios sich hinsichtlich seiner Verbindung zu Martina explizit auf alttestamentarisches Recht berief. Es ist jedoch allgemein anerkannt, dass das Alte Testament im Christentum der Spätantike als Referenzrahmen hoch im Kurs stand und dass gerade oströmische Kaiser sich in ihrer Herrschaftskonzeption und -ausübung mit alttestamentarischen Typen in Verbindung brachten bzw. im öffentlichen Diskurs mit diesen in Verbindung gebracht wurden. ${ }^{172}$ Dass auch Herakleios sich auf das Alte Testament bezog, zeigt der Umstand, dass einer der Söhne von Herakleios und Martina auf den Namen David getauft wurde ein Name, der keinesfalls zum Standardrepertoire monarchischer Nomenklatur zählte. ${ }^{173}$ Doch selbst wenn man diese Hypothese - die Berufung auf alttestamentarisches Recht - für plausibel hält, ist festzuhalten, dass dieser Aspekt der herakleischen Familienpolitik offenkundig in der Öffentlichkeit nicht auf Resonanz stieß; einer moralischen Verurteilung der Eheschließung beugte er jedenfalls nicht vor.

der durch den Patriarchen Sergios auf den Namen Konstantin getauft wurde. Dieser Konstantin, nicht zu verwechseln mit dem 612 geborenen Herakleios Konstantin, wird in keiner anderen Quelle erwähnt. Nik. Brev. 11 berichtet, dass Martina und Herakleios zwei Söhne mit Behinderung bekommen hätten, Flavius und Theodosios. Ebd. 18 wird vermerkt, dass zwei Söhne und zwei Töchter des Paares während des Perserkrieges verstorben seien. Theodosios war aber 629/39 noch am Leben, als er mit Nike, der Tochter des persischen Generals Shahrbaraz, vermählt wurde (Nik. Brev. 17). Insofern könnte man die beiden verstorbenen Söhne mit Konstantin und Flavius identifizieren; siehe Mango/Scott 1997, $431 \mathrm{f}$. Anm. 2. Während des Perserfeldzuges (625/626) kam schließlich ein weiterer Sohn zur Welt (Nik. Brev. 12), der 632 zum Caesar erhoben wurde. Er trug offenbar ebenfalls den Taufnamen Konstantin, zumindest gemäß dem Zeugnis des Theoph. Conf. AM 6108 (De Boor 301), der berichtet, wie Herakleios Konstantin seinen Bruder, den „kleinen Konstantin“, zum Caesar krönte. Es bleibt zu bemerken, dass Theophanes' Datierung falsch ist: Die Erhebung zum Caesar geschah in der 5. Indiktion, allerdings erwiesenermaßen erst einen Zyklus später, also 632 (siehe Mango/Scott 1997, 433 Anm. 2). Dieser Konstantin nahm dann den Namen Herakleios an, wie Datierungsformulare der 630er Jahre zeigen (siehe ebd.); unter diesem Namen wurde er 638 auch zum Augustus erhoben (Nik. Brev. 25 und De cerim. 2.27). In der Forschung firmiert er in der Regel unter dem Diminutiv Heraklonas; siehe dazu DOC II.2, 389f. und PLRE IIIA, Heraclonas (Heraclius) (587 f.). Nach dem Tod seines Vaters und Halbbruders Herakleios Konstantin im Jahr 641 war er für kurze Zeit alleiniger Augustus; Joh. Nik. 119.18 betont, er sei zu diesem Zeitpunkt noch ein Kind gewesen. Ihn mit dem Konstantin zu identifizieren, dessen Geburt Theophanes für das Jahr 615/6 vermerkt, ist daher nicht möglich.

$170 \mathrm{Zu}$ Endogamie im Christentum und Heiratskonventionen in der Spätantike siehe Mitterauer 1991 und O’Roark 1996; Mitterauer 1991, 299 zur Gesetzgebung im 4. Jahrhundert, die die Hochzeit von Onkel und Nichte unter Todesstrafe stellte; siehe das Verbot in Cod. Theod. 3.12.1.

171 Mitterauer 1991, 296.

172 Rapp 2010; Magdalino/Nelson 2010; zu alttestamentarischen Modellen für oströmische Kaiser im 6. Jahrhundert, insbesondere Salomon, siehe Viermann (im Druck).

173 In der Forschung wird oft Herakleios' Bezug auf den alttestamentarischen König David betont; diesen Befund diskutiere ich in unten S. 274-279 im Detail. Zu Herakleios' Sohn siehe PLRE IIIA, David 8 (390). 


\subsection{Abkehr von Konstantinopel}

Die Frage, die dieses Kapitel zu beantworten sucht, ist, warum es unter Herakleios zu einer sukzessiven Remilitarisierung des Kaisertums kam. Dass der Kaiser nach zweihundert Jahren der hauptstädtischen Monarchie mit etablierten Verhaltensweisen brach und wieder persönlich in den Krieg zog, ist in vielerlei Hinsicht erklärungsbedürftig. Wie bereits an anderer Stelle betont, brachte die Remilitarisierung des Kaisertums neue Herausforderungen mit sich. Herakleios' Syrien-Kampagne des Jahres 613 hatte die Risiken deutlich gemacht, die dem persönliche Engagement des Kaisers als Oberbefehlshaber inhärent waren: Die Niederlagen der römischen Truppen unter Herakleios’ Führung zeitigten nicht nur fatale Auswirkungen auf die Verteidigung Syriens und der Levante, sie brachten das Bild des Kaisers als ewiger Sieger, wie es sich im Laufe des 5. und 6. Jahrhunderts verfestigt hatte, empfindlich ins Wanken. Herakleios zog sich in Folge dessen nach Konstantinopel zurück und verbrachte das nächste Jahrzehnt wie seine Vorgänger im kaiserlichen Palast. Die Hochzeit mit seiner Nichte, setzt man diese wie oben nahegelegt ins Jahr 613/614 an, diente nach der erlittenen Niederlage der weiteren Sicherung und Konsolidierung seiner Familie als Herrscherdynastie - eine Strategie, deren Grundstein er bereits in den Jahren zuvor gelegt hatte.

Nachdem Herakleios 613 aus Syrien zurückgekehrt war, offenbarte sich langsam aber sicher das volle Ausmaß der außenpolitischen Krise, in die das oströmische Reich schlitterte. Die Niederlage bei Antiochia war bei weitem nicht die letzte, die das römische Heer gegen die Perser verbuchen musste. Seitdem sich die sassanidische Dynastie im Jahr 224 n.Chr. etabliert hatte, schwankte das Verhältnis der beiden Großmächte Rom und Persien zwischen kriegerischen Auseinandersetzungen und längeren Perioden des Waffenstillstandes. Auch im 6. Jahrhundert hielten sich diplomatische Bemühungen um Stabilität einerseits und gewaltsame Konfrontation andererseits die Waage, wobei die Perser bisweilen bis weit in römische Gebiete vordrangen: Nach der Eroberung Antiochias im Jahr 540 etwa hinterließen sie die Stadt in Schutt und Asche. ${ }^{174}$ Es war also nicht das erste Mal, dass persische Truppen derart weit im Westen standen, doch ihr Vorrücken im frühen 7. Jahrhundert zeichnete sich durch eine eigene Qualität aus: Während die Armee des Großkönigs zuvor nach Plünderungen stets wieder auf heimisches Territorium zurückgekehrt war - allein in den grenznahen Gebieten Mesopotamiens und Armeniens wechselte bisweilen die politische Oberhoheit - setzte sie sich nun auf römischem Territorium fest. Mit den Niederlagen von Herakleios' Truppen in Nordsyrien und Kilikien war die Landverbindung zwischen Konstantinopel und den süd-östlichen Provinzen abgeschnitten; den Persern stand der Weg nach Syrien und Palästina offen. Ohne Aussicht auf militärische Unterstützung kapitulierte Damaskus vor der Übermacht der Angreifer unter

174 Zu Römern und Sassaniden siehe zuletzt Börm 2016 und Bonner 2019, außerdem Greatrex/Lieu 2002. 
dem Befehl des persischen Generals Shahrbaraz; mit Caesarea Maritima fiel auch die Provinzhauptstadt Palästinas in dessen Hände. ${ }^{175}$

Im Jahre 614 schließlich ereignete sich eine Tragödie von außerordentlichem Ausmaß: Die Eroberung Jerusalems, des Zentrums des christlichen Glaubens, durch die Perser. Als Shahrbaraz' Truppen vor den Mauern der Stadt auftauchten, bemühte sich der Patriarch Zacharias um eine friedliche Übergabe - Gegenwehr schien auch hier angesichts der mangelhaften Verteidigungslage zwecklos. Doch die Jerusalemer Bevölkerung war gespalten; innerhalb der Zirkusparteien wurden Stimmen laut, dass die kampflose Auslieferung an den Feind nicht hinzunehmen sei. Die Situation eskalierte und es gelang, die Besatzer vorerst aus der Stadt zu vertreiben. ${ }^{176}$ Zacharias' Bemühungen, den Schaden in Grenzen zu halten, erwiesen sich als zwecklos: Nach mehreren Monaten der Belagerung kam es schließlich zur gewaltsamen Einnahme der Stadt. Die christlichen heiligen Stätten wurden geplündert und der Patriarch gemeinsam mit Teilen der Bevölkerung in die persische Hauptstadt Ctesiphon deportiert. Im Gepäck der Perser befand sich nicht zuletzt die wichtigste Reliquie der Christenheit, das Heilige Kreuz aus der Jerusalemer Grabeskirche. ${ }^{177}$ Im Zuge der Eroberung entluden sich schließlich auch Spannungen zwischen jüdischen und christlichen Bevölkerungsgruppen; Berichte von jüdischen Massakern an Christen machten die Runde. ${ }^{178}$ Die über Jahrhunderte aus Jerusalem verbannten Juden be-

175 Flusin 1992 II, 79 mit Anm. 54 und Greatrex/Lieu 2002, 190.

176 Ant. Strateg. (Conybeare 504f.) und Sebeos 34 (Thomson/Howard-Johnston I, 68f.); vgl. Flusin 1992 II, 142-147; zu den Demenunruhen in der Levante vgl. Olster 1993, 101-115. Bei Grabungen auf dem Giv'ati Parkplatz südlich der osmanischen Stadtmauern wurde ein Münzschatz mit 264 herakleischen Solidi gefunden; siehe Bijovski 2010. Deren Untersuchung hat ergeben, dass ausnahmslos alle Stücke nicht nur ins Jahr 613 datieren, sondern mit demselben Stempel geprägt wurden, aller Wahrscheinlichkeit nach in einer temporär eingerichteten Prägestätte in Jerusalem, welche die für die Verteidigung gegen die Perser notwendigen Geldmittel zur Verfügung stellen sollte. Das Vorhandensein des Stempels vor Ort, welcher hauptstädtischen Exemplaren extrem ähnelt, weist darauf hin, dass zumindest im Laufe des Jahres 613 noch offizielle Kommunikation zwischen Konstantinopel und Palästina möglich gewesen sein muss. Darüber hinaus offenbart das Gebäude, innerhalb dessen der Hort geborgen wurde, einen der wenigen Zerstörungshorizonte, die bisher mit der persischen Eroberung von Jerusalem verknüpft werden konnten.

177 Sophr. Anacr. 14.69-102 (Klage über die Eroberung); Ant. Strateg. (Conybeare 504-508); Chron. Pasch. AD 614; Sebeos 34 (Thomson/Howard-Johnston I, 68-70); Theoph. Conf. AM 6106 (De Boor 300 f.); weitere Quellen im Überblick bei Flusin 1992 II, 129-136. Zur Rekonstruktion der Ereignisse siehe Fulsin 1992 II, 151-172; Kaegi 2003, 78-81; Greisiger 2014, 32-45; Bonner 2019, 282-287; zu den Bewältigungsstrategien siehe Flusin 1992 II, 136-140.

178 Siehe etwa Ant. Strateg. (Conybeare 508; vgl. ebd. 514-516); Theoph. Conf. AM 6106 (De Boor 300 f.). Das Ausmaß der Zerstörung und der Massaker an der christlichen Bevölkerung wurde zuletzt wiederholt relativiert; vgl. Wheeler 1991; Avni 2010; Stoyanov 2011b und ders. 2011a, 11-23. Gleichzeitig hat allerdings auch archäologische Evidenz zum Verständnis der Geschehnisse 614 beitragen können: So wurde etwa nahe des Mamilla-Beckens ein Massengrab entdeckt, welches anhand einer beiliegenden Münze des Phokas plausibel mit der Eroberung Jerusalems - bzw. gar mit dem Bericht des Ant. Strateg. (Conybeare 508) - in Verbindung gebracht wird; siehe Reich 1993, 109; Avni 2010, 36 f., 39 f. mit Verweisen auf die Grabungsberichte; außerdem Bijovski 2010, 66. 
grüßten die Perser, von deren Präsenz sie offenbar zumindest vorübergehend profitieren konnten. Doch ihre Hoffnungen auf eine Wiedererrichtung des jüdischen Tempels, die zeitweilig geschürt wurden, sollten sich auch unter zoroastrischer Oberhoheit nicht erfüllen. ${ }^{179}$

Die Eroberung und Plünderung Jerusalem war der vorläufige Höhepunkt der desaströsen Entwicklungen im Osten, die sich nun auch in Konstantinopel kaum mehr verharmlosen ließen. Es gelang zwar, zwei Reliquien aus dem Heiligen Land in die Hauptstadt zu retten, den Heiligen Schwamm und den Heiligen Speer, die in der Hagia Sophia von der versammelten Gemeinde verehrt wurden; ${ }^{180}$ doch auch diese Inszenierung vermochte den tragischen Verlust des Heiligen Landes kaum zu kompensieren. Die Besetzung Syriens und Palästinas hatte das oströmische Reich wichtiger Einnahmequellen beraubt; der Krieg an der Ostgrenze und die diplomatischen Bemühungen, die Avaren im Westen ruhig zu halten, zehrten darüber hinaus an den finanziellen Reserven. Vor diesem Hintergrund ließ Herakleios ab dem Jahr 615 einen neuen Münztypus in Umlauf bringen, das Silber-Hexagramm, dessen Prägung mit einer gesetzlich vorgeschriebenen Halbierung des Edelmetall-Wertes einherging. ${ }^{181}$ Auch in seiner Gestaltung nahm das Hexagramm Bezug auf die prekäre Lage des römischen Reiches: Während auf dem Avers - wie auf den andere Nominalen auch die beiden Augusti Herakleios und sein ältester Sohn Herakleios Konstantin abgebildet waren, trug das Revers ein Stufenkreuz mit dem Schriftzug Deus adiuta Romanis - „Gott hilf den Römern“. ${ }^{182}$

Doch die göttliche Hilfe blieb vorerst aus. Im Jahr nach der Eroberung Jerusalems rückte der persische General Shahin mit seinen Truppen bis nach Chalkedon am Bosporus vor. Ein persisches Heer stand somit erstmals in Sichtweite der Hauptstadt. Die Römer waren sich ihrer Schwäche bewusst und darauf bedacht, den Schaden einzudämmen. Herakleios setzte mit einer Flotte über den Bosporus über und ehrte Shahin mit Geschenken. Nachdem beide Seiten sich auf die Entsendung einer römi-

$179 \mathrm{Zu}$ jüdischen Reaktionen auf die Eroberung Jerusalems siehe Wheeler 1991; Sivan 2000; Van Bekkum 2002; zuletzt Greisiger 2014, 46 - 62 mit der These, dass für kurze Zeit der jüdische Kult auf dem Tempelberg wieder eingerichtet werden konnte; vgl. dazu bereits Mango 1992, 3-6. Eine Zusammenstellung hebräischer Texte, die aus diesem Kontext heraus entstanden sind, findet sich bei Reeves 2006.

180 Chron. Pasch. AD 614; die Datierung der Reliquienüberführung wurde allerdings zuletzt wiederholt in Zweifel gezogen und anstatt für das Jahr 614 für 629 plädiert, also nach der Rückgewinnung der Ostprovinzen; dazu siehe die ausführliche Diskussion bei Speck 2000 und Klein 2001, beide mit Verweis auf Ericsson 1968, die von einer Störung des einzigen Manuskriptes des Chron. Pasch. ausgeht. Kaegi 2003, 189 übernimmt die Spätdatierung. Zu der Problematik mit der Passage im Chron. Pasch. siehe Whitby/Whitby 1989, 157 Anm. 438. Trotz berechtigter Bedenken halte ich die Datierung ins Jahr 614 für plausibler.

181 Siehe Chron. Pasch. AD 615 mit Anmerkung von Whitby/Whitby 1989, 158f. Anm. 441; auch die Bronze-Münzen wurden in den darauffolgenden Jahren in ihrem Wert reduziert (siehe ebd.) und Hendy 1985, $494 \mathrm{f}$.

182 Kaegi 2003, 90 f.; zum Hexagramm Yannopoulos 1978 und DOC II.1, 17-18, 115-117. 
schen Delegation nach Ctesiphon geeinigt hatten, zog Shahin ab. Tatsächlich machten sich drei hochrangige Männer auf den Weg nach Persien, ein demütiges Friedensgesuch im Gepäck. ${ }^{183}$ In der persischen Hauptstadt angekommen wurden die Hoffnungen allerdings schnell zunichte gemacht: Chosroes ging weder auf das römische Friedensgesuch ein noch gewährte er den Gesandten die Rückkehr in die Heimat. ${ }^{184}$ Der Großkönig war sich seiner überlegenen Stellung bewusst und nutzte diese gezielt aus: Nachdem die Perser sich in Palästina festgesetzt hatten, drangen sie ab 616 bis nach Ägypten vor; 619 fiel ihnen schließlich die letzte römische Bastion Alexandria in die Hände. ${ }^{185}$ In dem von den Langobarden bedrohten Italien brachen derweil wiederholt Unruhen aus; ein Usurpationsversuch des Exarchen von Ravenna, Eleutherios, der sich im Jahr 619 offenbar zum weströmischen Kaiser krönen lassen wollte, verlief allerdings schnell im Sande. ${ }^{186}$

Das erste Jahrzehnt von Herakleios' Regierung war alles andere als erfolgreich; das römische Gemeinwesen musste realpolitisch wie psychologisch harte Schläge einstecken. Ein Gebietsverlust von außerordentlichem Ausmaß schwächte Reich und Hauptstadt; von den östlichen Provinzen konnte nur Kleinasien noch mit Mühe und Not unter römischer Kontrolle gehalten werden, geschützt durch die Bergzüge, die das anatolische Plateau nach Osten und Süden abschranken. ${ }^{187}$ Der Schock, den die Plünderung Jerusalems und der Raub der Kreuzreliquie bei der Bevölkerung ausgelöst hatten, saß tief. Allgemeine Verunsicherung griff um sich. Liturgische Neuerungen deuten darauf hin, dass der Bedrohung durch eine gemeinschaftliche Intensivierung

183 Chron. Pasch. AD 615 (706-709); Act. Anast. Pers. 8; Sebeos 38 (Thomson/Howard-Johnston I, 78f.); Nik. Brev. 6f.; siehe auch Theoph. Conf. AM 6107 (De Boor 301). Hinsichtlich der Datierung von Shahins Vorstoß nach Chalkedon sind sich die Quellen uneins; bisweilen wird das Ereignis mit der Belagerung Konstantinopels 626 vermischt (so etwa Sebeos); vgl. die eingehende Rekonstruktion bei Flusin 1992 II, 83-93, außerdem Stratos 1968, 115-117; Mango 1990, 176f.; Thomson/Howard-Johnston 1999 II, 210 - 213 und Kaegi 2003, 83-86. Es spricht nichts gegen die Datierung ins Jahr 615, wie sie Chron. Pasch. gibt; der Eintrag gibt außerdem einen Brief des Konstantinopolitaner Senats an Chosroes II. wieder, der - wie andere offizielle Dokumente in dieser Chronik - als authentisch eingeschätzt werden kann.

184 Zum Schicksal der Gesandten siehe Nic. Brev. 7.

185 Zur Eroberung Ägyptens siehe Stratos 1968, 111-114; Kaegi 2003, 91-93; Howard-Johnston $1999,3$. 186 Lib. Pont. 71 (Bonifatius); Paul. Diac. Hist. Lang. 4.34; siehe PLRE IIIa, Eleutherius (435f.); Kaegi 2003, 93f.; Ravegnani 2011, 69f. Eleutherios war 616 als Exarch nach Ravenna gesandt worden, nachdem sein Vorgänger Johannes und dessen Stab einem Aufstand zum Opfer gefallen waren. Nach weiteren Auseinandersetzungen mit den Langobarden beanspruchte Eleutherios das weströmische Kaisertum; der genaue Anlass, der ihn zu diesem Schritt bewegte, ist kaum zu rekonstruieren. Er bat den Bischof von Ravenna, ihn zu krönen; dieser jedoch verwies darauf, dass Eleutherios dies lieber in Rom vom Papst vornehmen lassen solle. Auf dem Weg nach Rom wurde Eleutherios von kaisertreuen Truppen gestellt und ermordet; seinen Kopf schicke man nach Konstantinopel. Dazu, dass es immer wieder einmal zu Bemühungen kam, nach 476 erneut einen weströmischen Kaiser einzusetzen, siehe Börm 2008.

$187 \mathrm{Zu}$ der außerordentlich angespannten Lage, in der sich das oströmische Reiche befand, siehe Raum 2019, 135-138. 
öffentlicher Religiosität begegnet wurde. ${ }^{188}$ Ein Nachlassen der persischen Dominanz war indes nicht in Sicht; Chosroes' Truppen hatten sich in den eroberten Gebieten als neue Machthaber eingerichtet. ${ }^{189}$ In der Hauptstadt machte sich die Okkupation der Ostprovinzen mit fatalen Folgen für die Versorgungslage bemerkbar. Die kostenfreie öffentliche Brotversorgung, ein Privileg der hauptstädtischen Bevölkerung, wurde erst an den Preis von drei Bronze-Folles pro Laib gebunden und schließlich ganz ausgesetzt. ${ }^{190}$ Konstantinopel litt unter Hungernöten und einem erneuten Ausbrechen der Pest. ${ }^{191}$ Anfang der 620er Jahre war die Staatskasse derart beansprucht, dass Kirchenschätze aus dem Besitz der Hagia Sophia eingeschmolzen wurden, um die Vorräte an Gold- und Silbermünzen zur Finanzierung des Krieges aufzustocken. ${ }^{192}$

In diesem Zusammenhang berichtet Nikephoros, Herakleios habe angesichts der aussichtslosen Situation geplant, Konstantinopel $\mathrm{zu}$ verlassen und nach Libyen überzusetzen; er habe gar ein mit Reichtümern beladenes Schiff dorthin geschickt, das allerdings auf dem Weg gekentert sei. ${ }^{193}$ Nur die Initiative der hauptstädtischen Bevölkerung und des Patriarchen hätten den Kaiser dazu gebracht, von seinen Plänen abzurücken und in Konstantinopel zu bleiben. ${ }^{194}$ Die Authentizität dieser Episode ist fragwürdig, zumal das Breviarium (bzw. Nikephoros' Quelle) nachweislich wiederholt Ereigniszusammenhänge mit legendenhaften Elementen ausschmückt. ${ }^{195}$ Wie in den letzten Kapiteln deutlich wurde, zeichnete sich Herakleios' Handeln während seiner Usurpation, aber auch nach der Krönung durch ein hohes Maß an Verständnis machtpolitischer Zusammenhänge aus. Sich in die ehemalige Heimat abzusetzen, hätte seiner Herrschaft den Boden entzogen; die Hauptstadt am Bosporus hinter sich zu lassen und als Kaiser in Afrika zu residieren, war zu diesem Zeitpunkt schlicht-

188 Nach der Eroberung Jerusalems fanden zwei symbolträchtige Reliquien aus dem Heiligen Land ihren Weg nach Konstantinopel und wurden dort in der Hagia Sophia verehrt (Chron. Pasch. AD 614; siehe Diskussion des Datums oben S. 178 Anm. 180). Im Jahr darauf etablierte der Patriarch Sergios einen neuen liturgischen Gesang (Chron. Pasch. AD. 615). Dieser Prozess wird von Mischa Meier als Liturgisierung beschrieben; siehe etwa ders. 2016.

189 In Ägypten übernahmen die Perser die römischen Münzstätten, siehe Greatrex/Lieu 2002, 196. 190 Chron. Pasch. AD 618 (711) mit Anmerkungen von Whitby/Whitby 1989 164, Anm. 449.

191 Nik. Brev. 8, ähnlich ebd. 12. Die Pest brach offenbar auch in anderen Teilen des Reiches aus, siehe Kaegi 2003, 102-105.

192 Kirchenschätze: Theoph. Conf. AM 6113 (De Boor 302f.) und Nik. Brev. 11. Gemäß der Parast. synt. chron. 42.7-10 soll Herakleios auch den Bronze-Ochsen auf dem Theodosios-Forum eingeschmolzen haben, um Truppen zu finanzieren.

193 Reichtümer im Meer zu versenken scheint fürs frühe 7. Jahrhundert geradezu zum Topos geworden zu sein; angesichts der heranrückenden Flotte des Herakleios soll auch Phokas Staatsschätze ins Meer geworfen haben; siehe Joh. Nik. 110.4 und dazu Kaegi 2003, 88. Das Motiv, dass ein reich beladenes Schiff Richtung Libyen geschickt wurde, mag allerdings auch ein Reflex davon sein, dass Herakleios von Konstantinopel aus versuchte, die dortige Verteidigung gegen die Perser mit Ressourcen zu unterstützen.

194 Nik. Brev. 8; Kaegi 2003, 88f. mutmaßt, Herakleios habe versucht, die hauptstädtische Bevölkerung mit seinen Abwanderungsplänen unter Druck zu setzten, um seine Sparpolitik durchzubringen. 195 Diesen Sachverhalt werde ich in Bezug auf Nik. Brev. 24f. unten Kap. 6.2.2 im Detail zeigen. 
weg nicht möglich. Was Nikephoros als Herakleios’ Auswanderungspläne wiedergibt, sind meiner Ansicht nach Reflexe von Gerüchten, welche in Konstantinopel zirkulierten und die Verunsicherung der dortigen Bevölkerung zum Ausdruck brachten. ${ }^{196}$ Dass Versuche des regierenden Kaisers, sich graduell von Konstantinopel zu lösen, auf strikte Missbilligung stießen, hatte bereits Maurikios' vorsichtiger Vorstoß nach Thrakien einige Jahrzehnte zuvor unter Beweis gestellt. ${ }^{197}$ Unter Herakleios verhielt es sich nicht anders. Die Anwesenheit des Kaisers in Konstantinopel wurde gerade in prekären Situationen nicht nur vom Palast-Umfeld, sondern auch von der hauptstädtischen Bevölkerung eingefordert. Selbst Georg von Pisidien als Dichter panegyrischer Epen kam nicht umhin, die Irritation zu thematisieren, die sich in Konstantinopel Bahn brach, als der Kaiser sich sukzessive der hauptstädtischen Öffentlichkeit zu entziehen begann, um sich im Umkehrschluss dem Militär anzunähern und persönlich als Heerführer zu agieren. ${ }^{198}$

Im Jahr 622 verließ Herakleios tatsächlich erneut die Hauptstadt. Den Sommer 622 verbrachte er mit den römischen Soldaten in Kleinasien und konnte gar einen Sieg gegen persische Einheiten verzeichnen. Nachdem ihm die Avaren, die weiterhin Thrakien bedrängten, keine andere Wahl gelassen hatten, als in die Hauptstadt zurückzueilen und sich der Problematik persönlich anzunehmen, machte Herakleios sich im Frühjahr 624 wieder auf den Weg gen Osten. Diese Kampagne führte ihn über die Grenzen Kleinasiens hinaus bis ins persische Kernland. Was als eine sprichwörtliche Himmelfahrtsmission anmutet, zeitigte letztendlich den erhofften Erfolg. Der militärische Druck durch die Römer brachte die innerpersischen Machtverhältnisse in Bewegung: Chosroes II. wurde gestürzt und sein Sohn Kavadh Seiroe folgte ihm nach; der neue Großkönig sandte umgehend ein Friedensangebot an die Römer, das die Räumung der besetzten Provinzen beinhaltete. Mit dem Sieg im Rücken kehrte Herakleios nach über vier Jahren nach Konstantinopel zurück. ${ }^{199}$

Dass die Hauptstadt Herakleios in den Jahren der Abwesenheit die Treue halten und er nach über vier Jahren als Sieger würde zurückkehren können, war Anfang der 620er Jahre, als der Kaiser Konstantinopel erneut den Rücken kehrte, keinesfalls absehbar. Im Gegenteil: Der Machtwechsel von 610 hatte verdeutlicht, wie schnell die Stimmung in Konstantinopel kippen konnte. Die Hauptstadt im Jahr 622 für einen Sommer und ab 624 für mehrere Jahre am Stück zu verlassen, war für Herakleios demnach nicht etwa der logische bzw. folgerichtige Schritt, als der er in der Forschung bisweilen dargestellt wird. Stattdessen barg die kaiserliche Entscheidung eine Reihe

196 Bereits nach Phokas' Sturz habe Herakleios laut Chron. Pasch. AD 615 signalisiert, wieder nach Afrika zurückkehren zu wollen, da sein Ziel, der Sturz des Tyrannen und die Rache des Maurikios, erreicht sei. Es wurde bereits betont, dass hierin keine tatsächliche Absicht zu vermuten ist; stattdessen ist der Topos vom zögerlichen und demütigen Herakleios als Teil einer gezielten Repräsentationsstrategie zu verstehen; siehe oben S. 120 mit Anm. 196.

197 Theoph. Sim. Hist. 5.16.2-4.

198 Georg. Pis. Exped. Pers. 1.112-125; ähnlich ders. Heracl. 2.122-132.

199 Diese Abläufe werden im Detail unten S. 230 - 232 nachvollzogen. 
an schwerwiegenden Risiken: Neben dem Risiko der persönlichen Niederlage banden über Jahrhunderte gefestigte Verhaltenserwartungen den Kaiser an Konstantinopel; gegen diese Erwartungen zu verstoßen, konnte die Akzeptanzbasis der Hauptstadt empfindlich destabilisieren. Auch eine vermeintlich überragende militärische Expertise lässt sich kaum als Grundlage für die kaiserliche Entscheidung anführen, als Feldherr zu agieren. ${ }^{200}$ Herakleios stammte zwar aus einer Familie hochdekorierter und erfahrener Militärs (sein Vater hatte sich unter Maurikios als Magister militum im Perserkrieg hervorgetan); im Gegensatz zu seinen Vorgängern Phokas und Maurikios hatte er selbst jedoch vor seiner Krönung offenbar keine substantielle Erfahrung als aktiver Befehlshaber gesammelt. ${ }^{201}$ Die Eroberung Ägyptens hatte im Zuge der afrikanischen Revolte sein Cousin Niketas gestemmt. Erst als die Rebellen den südlichen Mittelmeerraum hatten militärisch sichern können, bestieg Herakleios ein Schiff und segelte unbehelligt bis nach Konstantinopel, wo die kurzen Kampfhandlungen in den Häfen primär zwischen den hauptstädtischen Parteien ausgefochten wurden. ${ }^{202} \mathrm{Ab}$ gesehen von dem gescheiterten Vorstoß nach Syrien im Jahr 613 hatte der Kaiser also keine bzw. wenig militärische Praxiserfahrung, als er sich 622 bzw. 624 erneut als Befehlshaber an die Spitze der römischen Truppen setzte. ${ }^{203}$

Herakleios’ Maßnahme ist kaum anders zu erklären, als dass ihm nach über einem Jahrzehnt auf dem Thron schlichtweg keine andere Wahl blieb, als die Flucht nach vorne zu wagen, um seine Herrschaft zu sichern. Hinsichtlich dieser Entscheidung griffen außen- und innenpolitische Faktoren aufs Engste ineinander. In der Regel wird Herakleios’ Entscheidung, persönlich die Position des Oberbefehlshabers einzunehmen, mit der geradezu aussichtslosen Situation in den Ostprovinzen in

200 Dies legt etwa Lee 2007, 37 nahe: „A man of his experience could not sit in Constantinople leaving others to get their hands dirty.” Allerdings sieht auch Lee die Gefahr, die für Herakleios vom militärischen Sektor ausging (siehe ebd.): „Perhaps the Phocas episode had made him and his advisers realize that, whatever the risks on the battlefield, it was not an option to distance himself from the army and risk another usurper emerging from that quarter.” Bisweilen wird gar auf den wagemutigen Charakter des Kaisers verwiesen; zudem habe ihm seine afrikanische Herkunft eine globale Perspektive auf römische Herrschaft ermöglicht, angesichts derer Konstantinopel an Bedeutung verloren habe; so etwa Pfeilschifter 2013, 68: „Der Kaiser war mit knapp 40 Jahren noch relativ jung und unternehmungslustig, seine erfolgreiche Usurpation gegen Phokas hatte in ihm vielleicht die Überzeugung reifen lassen, er sei ein überragender Feldherr, und, am wichtigsten, er hatte die meiste Zeit seines Lebens in der Provinz verbracht, fern vom Hof und fern von Konstantinopel. Die Stadt war ihm nicht unbedingt Maß aller Dinge, in seiner Erfahrungswelt umfasste das Reich wesentlich mehr als den Bosporus.“

201 Tatsächlich ist über Herakleios’ frühe Jahre in Africa recht wenig bekannt; vgl. die recht weit ausgeschmückte biographische Rekonstruktion in Kaegi 2003,19-57. Allerdings ist anzunehmen, dass die Quellen es in irgendeiner Form verzeichnet hätten, wenn Herakleios sich vor seiner Fahrt nach Konstantinopel militärisch hervorgetan hätte.

202 Dazu siehe oben Kap. 3.2.

203 Das mag auch der Grund dafür sein, dass Georg von Pisidien ausführlich thematisiert, wie Herakleios sich vor seinem Aufbruch nach Persien mit Büchern zurückgezogen habe, um Militärstrategie zu studieren; Georg. Pis. Heracl. 2.118-121. 
Verbindung gebracht: ${ }^{204}$ Die Aggression der Perser hatte bislang unbekannt Ausmaße angenommen und zeitigte destabilisierende Auswirkungen - sowohl materiell wie auch psychologisch - auf die sensible Gemengelage in Konstantinopel. Die in dieser Arbeit gewählte Perspektive legt allerdings nahe, dass Herakleios mit seiner Remilitarisierung nicht allein auf die Bedrohung durch die Perser, sondern auch auf innenpolitische Instabilität und eine latente Bedrohung aus dem militärischen Sektor reagierte. ${ }^{205}$ Konstantinopel war und blieb auch im frühen 7. Jahrhundert Dreh- und Angelpunkt monarchischer Herrschaft, die Akzeptanz der hauptstädtischen Gruppen deren Basis; dies hatten nicht zuletzt die beiden Machtwechsel von 602 und 610 gezeigt, die nur erfolgen konnten, da sich die relevanten hauptstädtischen Interessensgruppen von dem jeweils regierenden Kaiser abwandten. Gleichzeitig hatte sich allerdings auch herausgestellt, dass Impulse aus dem Militär die Stimmung in Konstantinopel wesentlich direkter beeinträchtigen konnten, als dies in den Jahrhunderten zuvor der Fall gewesen war. Herakleios hatte mit seiner geglückten Usurpation, die ihn von der Provinz in den kaiserlichen Palast katapultierte, die Probe aufs Exempel erbracht. Angesichts dieser Entwicklung bot Konstantinopel dem Kaiser keinen adäquaten Schutz mehr; an den Praktiken der sesshaften Vorgänger auf dem Kaiserthon festzuhalten, wie es noch sein Vorgänger Phokas getan hatte, reichte nicht mehr aus, um an der Macht zu bleiben. Indem Herakleios sich an die Spitze der römischen Truppen setzte, zielte er darauf ab, die kaiserliche Autorität über den militärischen Sektor zu festigen und damit potentiell destabilisierenden Impulsen, wenn nicht gar einer erneuten Usurpation, vorzubeugen. Anstatt den militärischen Sektor inmitten eines Perserkrieges ambitionierten und potentiell unberechenbaren Generälen zu überlassen, wie es seine Vorgänger getan hatten, setzte er sich selbst als oberster Feldherr an die Spitze der römischen Truppen. Mit seiner persönlichen Präsenz auf dem Schlachtfeld näherte Herakleios sich auch in wesentlich höherem Maße als seine sesshaften Vorgänger den römischen Soldaten an. Auf Seiten des Heeres wurde eine derart hergestellte Nahbeziehung sicherlich positiv aufgenommen; eine engere Bindung an den Kaiser versprach den Soldaten Prestige, wenn nicht gar konkrete materielle Vorteile. ${ }^{206}$

204 So etwa Treadgold 1997, 287-301; Walter E. Kaegi beleuchtet die Situation in seinen Publikationen aus verschiedenen Perspektiven: In Herakleios' Kampagnen von 612 und 613 sieht er dessen Versuch, die unruhige Armee wieder fester an den Kaiser zu binden (Kaegi 1981, 147 f.); hinsichtlich des erneuten Aufbruchs von 622 und 624 legt auch er nahe, dass dem Kaiser angesichts des Verlustes der Ostprovinzen keine andere Wahl geblieben sei (ders. 2003, 109). Howard-Johnston 2010, 252f. meint, Herakleios habe durch sein Feldherrentum von ,private affairs”, also der Ehe mit Martina, ablenken wollen. $205 \mathrm{Zu}$ der Frage nach den Hintergründen der Remilitarisierung des Kaisertums unter Herakleios vgl. Raum 2019; ebd. 144f., 146f. wird nahegelegt, dass es Herakleios daran gelegen war, die Loyalität der Soldaten zu ihm zu stärken.

206 Kurz nach seiner Rückkehr nach Konstantinopel 476 verkündete Kaiser Zenon den Soldaten, dass er sie im Kampf gegen die Goten anführen würde. Die Begeisterung auf Seiten der Soldaten, die eine derartige Nachricht auslöste, war allerdings nur von kurzer Dauer: Als Zenon sich doch für einen Verbleib in der Hauptstadt entschied, brach unter den Soldaten Unruhe aus, der der Kaiser nur be- 
Als Herakleios gen Osten aufbrach, musste er gegen die Zentripetalkräfte - die Verhaltenserwartungen der hauptstädtischen Interessengruppen - ankämpfen, die ihn nach Jahrhunderten der sesshaften Monarchie geradezu an Konstantinopel ketteten. Um die Erweiterung seines Handlungsspielraumes entgegen etablierter Konventionen durchsetzen zu können und gleichzeitig seine Akzeptanzbasis zu sichern, traf Herakleios eine Reihe praktischer Vorkehrungen. Während seine zweite Ehefrau Martina ihn auf dem Feldzug begleitete, ließ er, wie bereits bei der Syrien-Kampagne des Jahres 613, auch in den 620er Jahren seinen Sohn Herakleios Konstantin sowie dessen ältere Schwester, die Augusta Epiphania, in der Hauptstadt zurück. ${ }^{207}$ Damit im hauptstädtischen Beziehungsgeflecht keine Leerstelle entstand, die Anlass für eine erneute Usurpation hätte bieten können, kompensierte Herakleios die eigene Abwesenheit durch die Präsenz des Junior Augustus. Mit dem Patriarchen Sergios und dem Patrikios Bonos, der als Statthalter für den Kaiser agierte, installierte Herakleios ein operatives Führungsduo, das ihm in den Jahren seiner Abwesenheit von der Hauptstadt die Treue hielt. ${ }^{208}$

Herakleios’ Allianzen sowohl im klerikalen als auch im säkularen Feld erwiesen sich als erstaunlich stabil. Besonders in dem Patriarchen Sergios, der noch unter Phokas berufen worden war, fand Herakleios einen loyalen Verbündeten, der die Geschicke der Hauptstadt nicht nur in den Jahren kaiserlicher Abwesenheit verlässlich lenkte, sondern auch mit Herakleios an einem Strang zog, als es in den 630er Jahren darum ging, einen religionspolitischen Kompromiss zu erzielen. ${ }^{209}$ Dass Kaiser und Patriarch von Konstantinopel derart gut zusammenarbeiteten, war keinesfalls selbstverständlich: Im Laufe des 5. und 6. Jahrhundert waren die kirchliche und die weltliche Instanz wiederholt in erbitterten Machtkämpfen aneinandergeraten. ${ }^{210}$ Wie genau sich das persönliche Verhältnis zwischen Herakleios und Sergios gestaltete, ist kaum zu rekonstruieren; allerdings entsteht der Eindruck einer gegenseitigen Ab-

gegnen konnte, indem er die enttäuschten Soldaten vorzeitig auf die Winterquartiere verteilte und sich auf eine kostspielige diplomatische Lösung des Konfliktes mit den Goten einließ; siehe Malch. fragm. 18.3. Malchos begründet Zenons Rückzieher mit Feigheit; Pfeilschifter 2013, 63 dagegen meint, dass die Möglichkeit des persönlichen Scheiterns für Zenon doch zu riskant gewesen sei; weitere Erklärungsansätze für diesen Sinneswandel liefert Errington 1983.

207 Chron. Pasch. AM 624.

208 Theoph. Conf. AM 6113 (De Boor 303); die genaue Stellung des Bonos ist unklar; die Ämter des Magister militum praesentalis oder Magister officiorum stehen zur Debatte, siehe PLRE IIIa, Bonus 5 (242-244) und Haldon 1984, 444-446. Bonos vereinte offenbar militärische und zivile Kompetenzen. Nähere Informationen zu ihm sind nicht verfügbar; allerdings scheint es, dass er erst unter Herakleios Karriere machte und diesem entsprechend verpflichtet war. Dass Bonos noch vor dem Persersieg verstarb (Chron. Pasch. AD 627), mag für Herakleios, für den allzu große Machtfülle in einem weltlichen Amtsträger stets eine potentielle Bedrohung darstellen konnte, von Vorteil gewesen sein.

209 Besonders deutlich wurde der Wert von Sergios' Anwesenheit in Konstantinopel im Zusammenhang mit der Doppelbelagerung durch Perser und Avaren im Jahr 626; diese Konstellation untersuche ich unten Kap. 5.3 im Detail; zur Religionspolitik siehe unten Kap. 6.1.3.

210 Zu dem Verhältnis zwischen Kaisern und Patriarchen (bzw. der hauptstädtischen Geistlichkeit) siehe Pfeilschifter 2013, 355-451. 
hängigkeit: Herakleios musste - vor allem angesichts seiner Abwesenheit - auf Sergios als zentrale Autoritäts- und Identifikationsperson in Konstantinopel vertrauen können; Sergios profitierte von einem guten Verhältnis zum Kaiser insofern, als er die Herabsetzungen, die das Konstantinopolitaner Patriarchat unter Phokas hatte hinnehmen müssen, ${ }^{211}$ kompensieren und seine eigene Position stärken konnte. Doch loyale Verbündete allein reichten Herakleios kaum aus, um Konstantinopel über die langen Jahre seiner Abwesenheit zu sichern; im folgenden Kapitel wird deutlich, dass die kaiserliche Entscheidung, wieder persönlich als Feldherr zu agieren, auch kommunikativ bewältigt werden musste.

211 Dazu siehe oben S. 143. 